\title{
CLIC1 Promotes the Progression of Gastric Cancer by Regulating the MAPK/AKT Pathways
}

\author{
Bo-pei Lia Yuan-tian Mao ${ }^{a} \quad$ Zhen Wang ${ }^{a} \quad$ Ye-yang Chen ${ }^{b} \quad$ Ye Wang ${ }^{a}$ \\ Chong-yu Zhaia Bo Shia Si-yu Liu ${ }^{a}$ Jin-lu Liua Jun-qiang Chena \\ aDepartment of Gastrointestinal Surgery, The First Affiliated Hospital of Guangxi Medical University, \\ Nanning, Guangxi Province, 'Department of General Surgery, The First People's Hospital of Yulin, Yulin, \\ Guangxi Province, China
}

\section{Key Words}

Chloride intracellular channel 1 • Gastric cancer • Integrins • MAPKs • AKT

\begin{abstract}
Background/Aims: Chloride intracellular channel 1 (CLIC1), which is a member of the chloride channel protein family, is associated with various human tumors. Recent studies have shown that CLIC1 is involved in the occurrence and development of gastric cancer (GC). However, the exact mechanism remains unclear in GC. Methods: Effects of CLIC1 on the progression of GC in vivo and in vitro and the potential underlying mechanisms have been investigated by analysing 54 patients with GC, as well as human gastric cell lines SGC-7901 and MGC-803, utilizing proteomics, RT-PCR, Western blotting, flow cytometry, Cell invasion and migration assays and xenograft tumor models. Results: Our study shows that CLIC1 knockdown by targeted-siRNA markedly inhibits GC cell invasion and migration and induces apoptosis in vitro. In total, 54 differentially expressed proteins were identified in GC cells SGC-7901 after CLIC1 silencing by isobaric tags for relative isotope labeled and absolute quantitation (iTRAQ) technology, including integrin $\alpha 1$ (ITG $\alpha 1$ ) and ITG $\alpha 3$. The expression levels of ITG $\alpha 3$, ITG $\alpha$, ITG $\beta 1$ and Bcl2 mRNA and protein were decreased significantly in GC cells after CLIC1 knockdown; ITG $\alpha 1$ and Fas were upregulated, but the level of survivin was not significantly different. GC growth and metabolism were decreased in vivo after CLIC1 silencing, but apoptosis was markedly increased. Further study showed that the expression levels of ITG $\alpha 3$, ITG $\alpha$ v and ITG $\beta 1$, as well as AKT-phosphorylation, ERK-phosphorylation and p38-phosphorylation, were reduced in vivo after CLIC1 knockdown, while ITG 1 1 was upregulated. Conclusions: We speculate that CLIC1 may play an important role in the progression of GC, and its mechanism may be related to the regulation of integrin family proteins, which leads to the sequential regulation of the PI3K/AKT, MAPK/ERK and MAPK/p38 pathways.
\end{abstract}

B.-P. Li and Y.-T. Mao contributed equally to this work. 


\section{Introduction}

Gastric cancer (GC) is a gastrointestinal malignancy originating from the epithelium and is one of the most common malignant tumor types. An estimated 951, 600 new GC cases and 723, 100 deaths occurred worldwide in 2012. Recent studies have shown that GC was the second leading cause of cancer death worldwide, accounting for $6.8 \%$ of cancer incidence and $8.8 \%$ of cancer deaths [1]. To date, multimodal treatment strategies, including chemotherapy, radiotherapy, and surgery, have limited the progression of tumors remarkably, and the rate of systemic metastasis has been substantially reduced. However, tumor metastasis and recurrence are the main causes of death of GC patients. Additionally, the mechanisms underlying the invasion and metastasis of GC remain to be elucidated.

Chloride intracellular channel 1 (CLIC1) was the first protein identified from the CLIC family, and is the most studied family member. CLIC1 is located on human chromosome 6 p21.3, with a total length of 1, 223 basepairs that encode a 241-amino acid ion channel protein. CLIC1 may play an important role both in the normal physiological cell state and the development of tumors because it is expressed in the cell nucleus, cytoplasm and cell membrane [2]. CLIC1 may be involved in the physiological cell state, such as changes in cell volume, the regulation of membrane potential, the acidification of intracellular organelles, the proliferation and differentiation of cells and cell cycle progression. However, the abnormal expression of CLIC1 can lead to abnormal physiological regulation and may affect the occurrence and development of tumors, especially in terms of invasion and metastasis [3].

Early studies have demonstrated the role of CLIC1 in invasion and metastasis in several malignant tumor types, such as liver cancer, colorectal cancer and prostate cancer, indicating that it may play an important role in the progression of cancer [4-6]. Recently, Chen et al. [7] reported that the CLIC1 protein was over-expressed in human GC tissues, and its expression was correlated with lymph node metastasis, lymphatic vessel and nerve infiltration, pathological stage and survival rate. Zheng et al. [8] confirmed that the over-expression of CLIC1 promoted the invasion and metastasis of GC cells. Additionally, knockdown of CLIC1 via transient transfection was shown to suppress invasion and metastasis of GC cells. Since the mechanisms involving signaling pathways regulated by CLIC1 remain unclear in GC, we designed this study to investigate the effect of CLIC1 silencing on apoptosis, migration and invasion of GC in vitro and in vivo, aiming to explore potential molecular signaling pathways.

\section{Materials and Methods}

Ethics approval

This study was approved by the Ethical Review Committee of the First Affiliated Hospital of Guangxi Medical University. Written informed consent was obtained from all patients.

\section{Study population}

In total, 54 patients (38 males and 16 females) with GC diagnosed between 2013 and 2015 were enrolled in this study. Each patient had undergone gastric resection (22 total gastrectomies and 32 partial gastrectomies). The study protocol was approved by the Medical Ethics and Human Clinical Trial Committee at the First Affiliated Hospital of Guangxi Medical University. We collected the following data: patient age and gender; tumor size; lymph node metastasis; distant metastasis; pathological type; and TNM stage. Pathological type features were classified as two types: (i) poorly differentiated adenocarcinoma; and (ii) undifferentiated, mid-differentiated or well differentiated.

Cell culture

The human gastric cell lines SGC-7901 and MGC-803 were procured from the cell bank of the Chinese Academy of Science (Shanghai, China). All cells were cultured in RPMI-1640 medium (HyClone, Logan, UT, USA) supplemented with $10 \%$ fetal bovine serum (HyClone, Logan, UT, USA) at $37^{\circ} \mathrm{C}, 5 \% \mathrm{CO}_{2}$ in a standard humidified incubator. Cells in the logarithmic phase were used for the experiments. 


\section{Lentivirus-mediated RNA interference (RNAi)}

For lentivirus-mediated silencing of CLIC1 (NM_001288.4), one effective sequence of human CLIC1siRNAs (small interference RNAs) was selected, as follows: 5'-GCCAAAGUUACACAUAGUATT-3'. Another fragment with the scrambled sequence (5'-TTCTCCGAACGTGTCACGT-3') had no significant homology to human and mouse gene sequences and was chosen as a negative control siRNA. These siRNAs were synthesized and inserted into the GV115 lentivirus vector. The positive clones were verified by DNA sequencing. Then, the recombinant lentivirus was packaged and concentrated, and the final virus titer was determined. SGC-7901 and MGC-803 cells were infected with the recombinant lentivirus at a multiplicity of infection of 40 and 10, respectively, for $16 \mathrm{~h}$. The medium was then replaced with fresh medium. The cells were observed under fluorescence microscopy after 3 days.

\section{qRT-PCR}

Total RNA was extracted using Trizol reagent (Invitrogen, Carlsbad,CA,USA) according to the manufacturer's instructions. The concentration and purity of the RNA samples were detected at $260 \mathrm{~nm}$. First-strand cDNA was generated through reverse transcription with reverse transcriptase (Promega, Madison, WI, USA). The specific primers were synthesized by Genechem (Shanghai, China) as follows: GAPDH, 5'-TGACTTCAACAGCGACACCCA-3' (forward) and 5'-CACCCTGTTGCTGTAGCCAAA-3'(reverse);CLIC1, 5'-ACCGCAGGTCGAATTGTTC -3 '(forward) and 5'-ACGGTGGTAACATTGAAGGTG -3'(reverse); ITG $\alpha 1$, 5'-GTGATAGGAGCTCCGCTGGAA-3' (forward) and 5'-ACATCTGTCAGACCGTCACCATTTA-3'(reverse); ITG $\alpha 3$, 5'-ATTATTGAGGACATGTGGCTTGGAG-3' (forward) and 5'-TGACCACAGCACCTGGGTGTA-3'(reverse); ITG $\alpha$, 5'-AAACTCGCCAGGTGGTATGTGA-3'(forward) and 5'-CTGGTGCACACTGAAACGAAGA-3'(reverse); ITG $\beta 1$, 5'-AGCTGAAGACTATCCCATTGACCTC-3'(forward) and 5'-TGGTGTTGTGCTAATGTAAGGCATC-3'(reverse). SYBR Premix Ex Taq (TaKaRa, Dalian, China) was used for real-time PCR, and the total reaction volume was $20 \mu \mathrm{l}$. The cycling conditions included a holding step at $95^{\circ} \mathrm{C}$ for $30 \mathrm{~s}$, and 45 cycles done in two steps: $5 \mathrm{~s}$ at $95^{\circ} \mathrm{C}$ and $30 \mathrm{~s}$ at $60^{\circ} \mathrm{C}$, and a dissociation step was added to verify that each primer pair produced only a single product at $15 \mathrm{~s}$ at $95^{\circ} \mathrm{C}, 30 \mathrm{~s}$ at $55^{\circ} \mathrm{C}$ and $15 \mathrm{~s}$ at $95^{\circ} \mathrm{C}$. GAPDH was used as the internal control, and gene expression was quantified using the $2^{-\Delta c t}$ method.

ITRAQ (isobaric tag for relative and absolute quantitation) screening of differential proteomics

The cells were harvested for the analysis of protein expression and lysed on ice using RIPA lysis buffer (Beyotime Biotechnology, Shanghai, China). The protein concentration of the lysate was determined by the bicinchoninic acid assay (Beyotime Biotechnology, Shanghai, China). The total protein was digested with Trypsin (Beyotime Biotechnology, Shanghai, China) with the ratio of protein: $\operatorname{tryp} \sin =40: 1$ at $37^{\circ} \mathrm{C}$ for $16 \mathrm{~h}$. After trypsin digestion, the peptides were dried by vacuum centrifugation. ITRAQ labeling was carried out based on the manufacturer's instructions and each experiment was performed in two biological replicates. The peptides were labeled with the iTRAQ Reagents Multiplex kit (Applied Biosystems, Foster City, CA, USA) and were reconstituted in $70 \mu \mathrm{L}$ ethanol. The control sample and CLIC1siRNA sample were labeled with ITRAQ reagents 114 and 115, respectively. All tagged samples were incubated for $1 \mathrm{~h}$ at room temperature and were then pooled together and lyophilized to powder.The labeled samples were purified using a strong cation exchange chromatography (SCX) column (Phenomenex Inc.,Torrance, CA, USA) and separated by liquid chromatography(LC) using the LC-20AB HPLC Pump system.The iTRAQ-labeled peptide mixtures were dissolved in $200 \mu \mathrm{L}$ buffer $\mathrm{A}$ [ $10 \mathrm{mM} \mathrm{NaH}_{2} \mathrm{PO}_{4}$ in $20 \% \mathrm{ACN}$ (acetonitrile), $\mathrm{pH} 3.0$ ] and loaded onto a 100 $\times 2.1 \mathrm{~mm}$ Ultremex SCX column (Phenomenex) containing $5-\mu \mathrm{m}$ particles. The mobile phase consisted of buffer A, and buffer B (10 $\mathrm{mM} \mathrm{KH}_{2} \mathrm{PO}_{4}, 500 \mathrm{mM} \mathrm{KCl}$, and $\left.20 \% \mathrm{ACN}, \mathrm{pH} 3.0\right)$ was set at a flow rate of $0.25 \mathrm{ml} /$ min. An optimized gradient elution mode was carried out as follows: $0-15 \mathrm{~min}, 0 \% \mathrm{~B} ; 15-50 \mathrm{~min}, 0 \%-40 \% \mathrm{~B}$; 50-55min, 40\%-100\%B;55-63min, 100\%B; 63-65 min, 100\%-0\% B.Elution was monitored by measuring the absorbance at $214 \mathrm{~nm}$, and fractions were collected every $1 \mathrm{~min}$. The eluted peptides were pooled into 20 fractions, desalted with a Strata X C18 column (Phenomenex Inc.,Torrance, CA, USA) and vacuum-dried [9].The nanoscale HPLC system (EASY-nLC from Proxeon Biosystems) connected to an Orbitrap Q Exactive equipped with a nanoelectrospray source was used to separate the peptides, and then the peptide samples were loaded onto the EASY C18 column (Thermo Scientific) after reconstituting in mobile phase A (2\% $\mathrm{ACN}$ and $0.1 \%$ formic acid). The liquid phase condition was performed as follows: flow rate of $300 \mathrm{nl} / \mathrm{min}$; $0-5 \mathrm{~min}, 0 \% \mathrm{~B}(98 \% \mathrm{ACN}$ and $0.1 \%$ formic acid); 5-50min,5\%-35\%B; 50-52min, 35\%-100\%B;52-55min, $100 \%$ B. The effluent from HPLC was directly electrosprayed into the mass spectrometer for analysis [10], then the SEQUEST Cluster software was used to search the Uniprot (http://www.uniprot.org/), IPI(http:// 


\section{Cellular Physiology Cell Physiol Biochem 2018;46:907-924 and Biochemistry Published online: April17, $2018 \quad \begin{aligned} & \text { DOI: 10.1159/000488822 } 2018 \text { The Author(s). Published by S. Karger AG, Basel } \\ & \text { www.karger.com/cpb }\end{aligned}$}

Li et al.: CLIC1 Promotes the Progression of Gastric Cancer

www.ebi.ac.uk/IPI/) and NCBI (https://www.ncbi.nlm.nih.gov/) databases for differentially expressed proteins.

\section{Western blotting}

The protein extraction and concentration determination were similar to the above-mentioned method. Forty micrograms of protein sample per well were resolved by SDS-PAGE and transferred to a PVDF membrane and blocked with 5\% BSA (bull serum albumin) in TBST (Tris buffered saline and Tween 20). The membrane was incubated with primary antibodies against Bcl-2(Cell Signaling Technology, Danvers, MA, USA), survivin (Cell Signaling Technology), Fas(Cell Signaling Technology), ITG $\alpha$ (Abcam, Cambridge, MA, UK), ITG $\alpha 1$ (Abcam), ITG $\alpha 3$ (Abcam), ITG $\beta 1$ (Abcam) and $\beta$-actin(Cell Signaling Technology) and were then incubated with HRP-conjugated secondary antibody (Cell Signaling Technology). Immunoreactivity signals were developed using the ECL reagent (Beyotime Biotechnology) and recorded by a fluorescence detection system.

\section{Cell apoptosis analysis}

An annexin V-PE Apoptosis Detection Kit (Becton Dickinson, San Diego, CA, USA) was used to detect cell apoptosis following the manufacturer's instructions. In brief, the cells were collected by centrifugation at $2000 \mathrm{rpm}$ for $5 \mathrm{~min}$. After washing, the cells were resuspended in $100 \mu$ lof annexin V binding buffer, then $5 \mu \mathrm{l}$ annexin V-PE and $5 \mu \mathrm{l}$ 7-Amino-actinomycin D were added to the solution. After incubation in the dark for $15 \mathrm{~min}$ at room temperature, $400 \mu$ lof binding buffer was added, and the cells were subjected to flow cytometry (FCM).

\section{Cell invasion and migration assay}

The invasive capacity of the cells after transfection was measured using a Transwell chamber assay. Matrigel (Becton Dickinson) was put into a $4^{\circ} \mathrm{C}$ refrigerator overnight to melt. The next day, the Matrigel concentration was diluted by $1.25 \mathrm{mg} / \mathrm{ml}$ with serum-free medium, and $50 \mu$ l Matrigel was added to the upper chamber of each Transwell insert (pore size $8 \mu \mathrm{m}$, Corning, NY, USA). Next, they were incubated at $37^{\circ} \mathrm{C}$ for $5 \mathrm{~h}$ to convert the Matrigel from liquid to gelatin. After hydration of the Matrigel with serum-free medium, $100 \mu \mathrm{l} \mathrm{SGC-7901} \mathrm{and} \mathrm{MGC-803} \mathrm{cells} \mathrm{with} \mathrm{a} \mathrm{density} \mathrm{of} 3 \times 10^{5} / \mathrm{ml}$ and $2 \times 10^{5} / \mathrm{ml}$, respectively, were placed in the upper chamber of each Transwell insert, and 500 $\mu$ l of RPMI 1640 supplemented with $10 \%$ fetal bovine serum was added to the lower compartment of the cell culture insert.After a 24-h incubation at $37^{\circ} \mathrm{C}$ in $5 \% \mathrm{CO}_{2}$, the cells on the upper surface of the Transwell insert were completely removed by wiping with a cotton swab. The invaded cells that remained on the lower surface of the filter were fixed and stained with $1 \%$ crystal violet (Sigma-Aldrich, USA) solution and 10\% ethanol. The stained cells in five randomly selected microscopic fields per filter were counted. A cell migration assay was also performed using a Transwell chamber assay (pore size $8 \mu \mathrm{m}$, Corning,NY, USA) without Matrigel. Other treatments were the same as the cell invasion assay.

\section{Orthotopic xenografted tumor models}

The animal experimentswere approved by the Animal Ethics Committee of The First Affiliated Hospital of Guangxi Medical University. Female BALB/C nude mice (5-6 weeks old, weighing about 18-20g) were housed in an animal facility with $50 \%-65 \%$ relative humidity, $22^{\circ} \mathrm{C}-24^{\circ} \mathrm{C}$ environmental temperatureand a 12-h light/dark cycle. The BALB/C nude mice were randomly divided into threegroups ( $\mathrm{n}=6 /$ group). Then, CLIC1 knockdown or siRNA control SGC-7901 and MGC-803 cells $\left(6 \times 10^{7}\right.$ in $200 \mu$ l medium) were injected subcutaneously into the armpit area. However, the MGC-803-KD xenografted tumor model failed even when the experimental conditions were optimized. Through a literature search, we found that an siRNA with a special chemical modification (chol-siRNA) can be directly injected into specific tissues or organs to silence a target gene [11]. Thus, both CLIC1-chol-siRNA and MGC-803 cells were injected subcutaneously into the armpit area, and MGC-803-chol subcutaneous tumors were successfully established. The subcutaneous tumors were sliced and inoculated in the armpit area again. Then, the subcutaneous tumors of the second generation were sliced for constructing orthotopically transplanted tumors. The tumor volume was calculated by $0.5 \times$ length $\times$ width $^{2}$. Protein Simple Wes (WES) technology was used to detect the protein expression from the tumor tissues. The validation of transplanted tumor tissues was tested by hematoxylineosin (HE) staining, and cell apoptosis of the tumor tissues was detected using the terminal deoxynucleotidyl 


\section{Cellular Physiology \begin{tabular}{l|l} 
and Biochemistry Published online: April 17, 2018 & $\begin{array}{l}\text { () 2018 The Author(s). Published by S. Karger AG, Basel } \\
\text { www.karger.com/cpb }\end{array}$ \\
\hline
\end{tabular} \\ Li et al.: CLIC1 Promotes the Progression of Gastric Cancer}

transferase-mediated dUTP nick end-labeling (TUNEL) Assay by 3, 3'-Diaminobenzidine (DAB) and fluorescence staining. The lymph node metastasis and metabolic status of the orthotopically transplanted tumors were evaluated using PET-CT. The protein content of the tumors was detected using WES assays [12, 13], and the primary antibodies were as follows: CLIC1(Abcam), GAPDH(Cell Signaling Technology), Bcl-

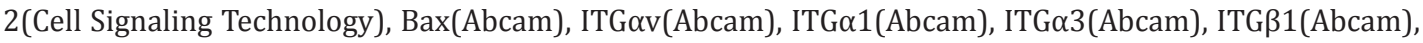
ERK(Cell Signaling Technology), p-ERK(Cell Signaling Technology),AKT(Abcam), p-AKT (Abcam),p38(Cell Signaling Technology) and p-p38(Cell Signaling Technology).

Statistical analysis

All experiments were performed at least in triplicate.The datais expressed as mean $\pm \operatorname{SD}$ (standard deviation). Differences among the means of multiple groups were compared using analysis of variance (ANOVA). The t test was used to compare the difference between two groups. Statistical significance was determined at $P<0.05$.

\section{Results}

\section{Association of CLIC1 expression with clinicopathological characteristics}

Representative staining results of CLIC1 are presented in Fig. 1A-B, which show the expression of the protein in the cytoplasm and nucleus. The results show that CLIC1 staining in GC was higher than that of adjacent noncancerous tissue $(P<0.001)$ (Fig. 1C). Clinicopathological characteristics including patient sex, age, whether lymph node metastasis occurred, whether distant metastasis occurred, pathological type and TNM stage of the patients enrolled in this study are listed in Table 1. As shown,a higher CLIC1 positive rate was observed in patients with distant metastasis than in those without metastasis $(P<0.001)$. Moreover, higher CLIC1 expression was observed in patients with the worst TNM stage $(P=0.028)$.

GC cell lines with low CLIC1 expression were constructed

The CLIC1-siRNA sequence was successfully inserted into the GV115 lentivirus vector and the positive clones were verified by DNA sequencing (Fig. 2A). The cell transfection was performed by lentivirus-mediated RNAi. The transfection efficiency was evaluated under a fluorescence microscope. Our results showed that the transfection efficiency was over $80 \%$ in both SGC7901 and MGC-803 cells (Fig. 2B-C). The CLIC1 mRNA expression in SGC-7901 and MGC-803 cells was significantly lower than that in the negative control (NC) and blank control (CON) groups after lentivirus-mediated RNAi $(P<0.05)$.The inhibition rate was over $85 \%$ in both SGC-7901 and MGC-803 cells (Fig. 2D-E).

\section{CLIC1 inhibits apoptosis of GC in vitro}

Apoptosis was detected using FCM. The apoptosis rate of the knock down (KD) group was significantly higher than that of the CON group in SGC-7901 $(25.52 \%$ vs $12.67 \%, P<0.05)$ and

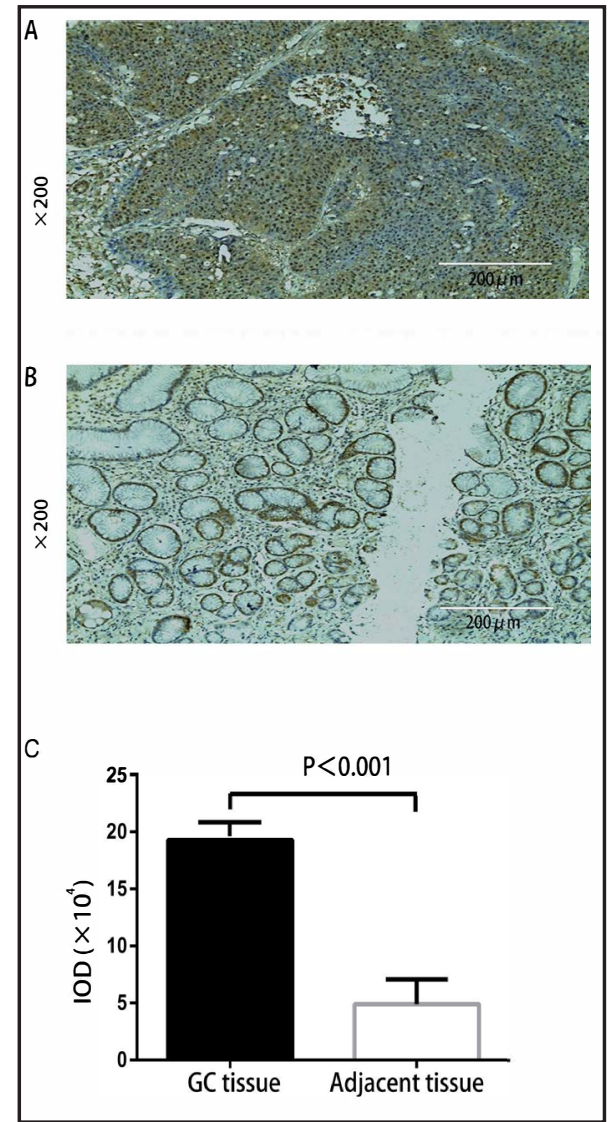

Fig. 1. Expression of the CLIC1 protein in GC and adjacentnoncancerous tissue of GC patients. Positive staining for CLIC1 was found mainly in the GC-adjacent noncancerous tissue $(200 \times)$ (A, B). Expression of CLIC1 staining between GC and adjacent noncancerous tissue (C). 
MGC-803 cells $(17.90 \%$ vs $6.09 \%, P<0.05)$. There was no significant difference in the apoptosis rate between the CON and NC groups $(P>0.05) \quad$ (Fig. 3A-D). This suggests that CLIC1 silencing promotes the apoptosis of GC cells. We further detected the expression levels of apoptosisrelated proteins (Bcl-2 and survivin), and the results showed that CLIC1 silencing significantly suppressed Bcl-2 protein expression in both SGC-7901 and MGC803 cells $(P<0.05)$, while the survivin protein expression was not significantly different between the $\mathrm{KD}$ and $\mathrm{CON}$ groups in both SGC-7901 and MGC-803 cells $(P>0.05)$ (Fig. 3E-F). Moreover, the expression levels of these proteins were similar between the $\mathrm{CON}$ and $\mathrm{NC}$ groups $(P>0.05)$ (Fig. 3E-F).

CLIC1 promotes GC cell migration and invasion in vitro

The migration assay revealed that the numbers of both SGC-7901 and MGC-803 cells crossing the membrane in the KD group were reduced significantly when compared with CON group cells $(118.33 \pm 8.51$ vs $181.67 \pm 11.72, \quad 108.67 \pm 8.33$ vs $185.00 \pm 11.00 ; \quad P<0.05)$
Table 1. Association of expression of CLIC1 with clinicopathological characteristics in gastric cancer [n (\%)]. Note: \#The 7thTNM Classification of Malignant Tumors proposed by the AJCC/UICC

\begin{tabular}{|c|c|c|c|}
\hline Variable & Total patients(n=54) & Positive No.(\%) & $P$ \\
\hline \multicolumn{4}{|l|}{ Sex } \\
\hline Female & 16 & $9(56.3)$ & 0.762 \\
\hline Male & 38 & $24(63.2)$ & \\
\hline \multicolumn{4}{|l|}{ Age, years } \\
\hline$\leq 58 \quad($ median age $)$ & 27 & $15(55.6)$ & 0.577 \\
\hline$>58 \quad($ median age $)$ & 27 & $18(66.7)$ & \\
\hline \multicolumn{4}{|l|}{ Size (maximal diameter) } \\
\hline$<5 \mathrm{~cm}$ & 29 & 17(58.6) & 0.783 \\
\hline$\geq 5 \mathrm{~cm}$ & 25 & $16(64.0)$ & \\
\hline \multicolumn{4}{|l|}{ Lymph node metastasis } \\
\hline Yes & 39 & $25(64.1)$ & 0.541 \\
\hline No & 15 & $8(53.3)$ & \\
\hline \multicolumn{4}{|l|}{ Distant metastasis } \\
\hline Yes & 17 & $12(70.6)$ & 0.001 \\
\hline No & 37 & $11(29.7)$ & \\
\hline \multicolumn{4}{|l|}{ Pathological type } \\
\hline low differentiated adenocarcinoma & 34 & $20(58.8)$ & 0.775 \\
\hline other & 20 & $13(65.0)$ & \\
\hline \multicolumn{4}{|l|}{ TNM stage \# } \\
\hline Stage I & 15 & $8(53.3)$ & 0.067 \\
\hline Stage II & 8 & $2(25.0)$ & \\
\hline Stage III & 15 & $12(80.0)$ & \\
\hline Stage IV & 16 & $11(68.8)$ & \\
\hline \multicolumn{4}{|l|}{ TNM stage \# } \\
\hline Stage I, II & 23 & $10(43.4)$ & 0.028 \\
\hline Stage III,IV & 31 & $23(74.2)$ & \\
\hline
\end{tabular}

(Fig. $4 \mathrm{~A}-\mathrm{B}, 4 \mathrm{E}$ ), and the migration inhibition rates were $34.87 \%$ and $41.26 \%$, respectively. The invasion assay also displayed similar findings $(86.00 \pm 6.00$ vs $156.67 \pm 14.84,81.33 \pm 5.03$ vs $168.33 \pm 17.39 ; P<0.05$ ) (Fig. $4 \mathrm{C}-\mathrm{D}, 4 \mathrm{~F}$ ), and the invasion inhibition rate was $45.11 \%$ and51.68\%in SGC-7901 and MGC-803 cells, respectively. In conclusion, down-regulating CLIC1 expression inhibits the migration and invasion abilities of SGC-7901 and MGC-803 cells.

\section{Protein mass spectrometry analysis of GC cells SGC-7901 after CLIC1 silencing}

We set the protein content ratio of SGC-7901 and SGC-7901-KD more than 2.0 or less than 0.5 as differentially expressed proteins, and then we used SEQUEST Cluster software to search the Uniprot, IPI and NCBI data bases. The results revealed that there were 36 upregulated and 18 down-regulated differentially expressed proteins from the SGC-7901 and SGC-7901-KD groups after CLIC1 silencing, including two ITGs, ITG $\alpha 1$ and ITG $\alpha 3$ (Tables 2 KARGER 
Fig. 2. The sequence diagram of the lentivector (segment) and transfection of GC cells. The yellow mark indicates the CLIC1-siRNA sequence (A).Transfection efficiency of GC cell lines SGC7901(100x) (B) and MGC803 (100×) (C). CLIC1 mRNA expression levels were significantly suppressed in SGC-7901 cells (D) and MGC803 cells (E) after lentivirus-mediated CLIC1-siRNA transfection $\quad\left({ }^{*} P<0.05 \quad\right.$ vs blank control and negative control groups).

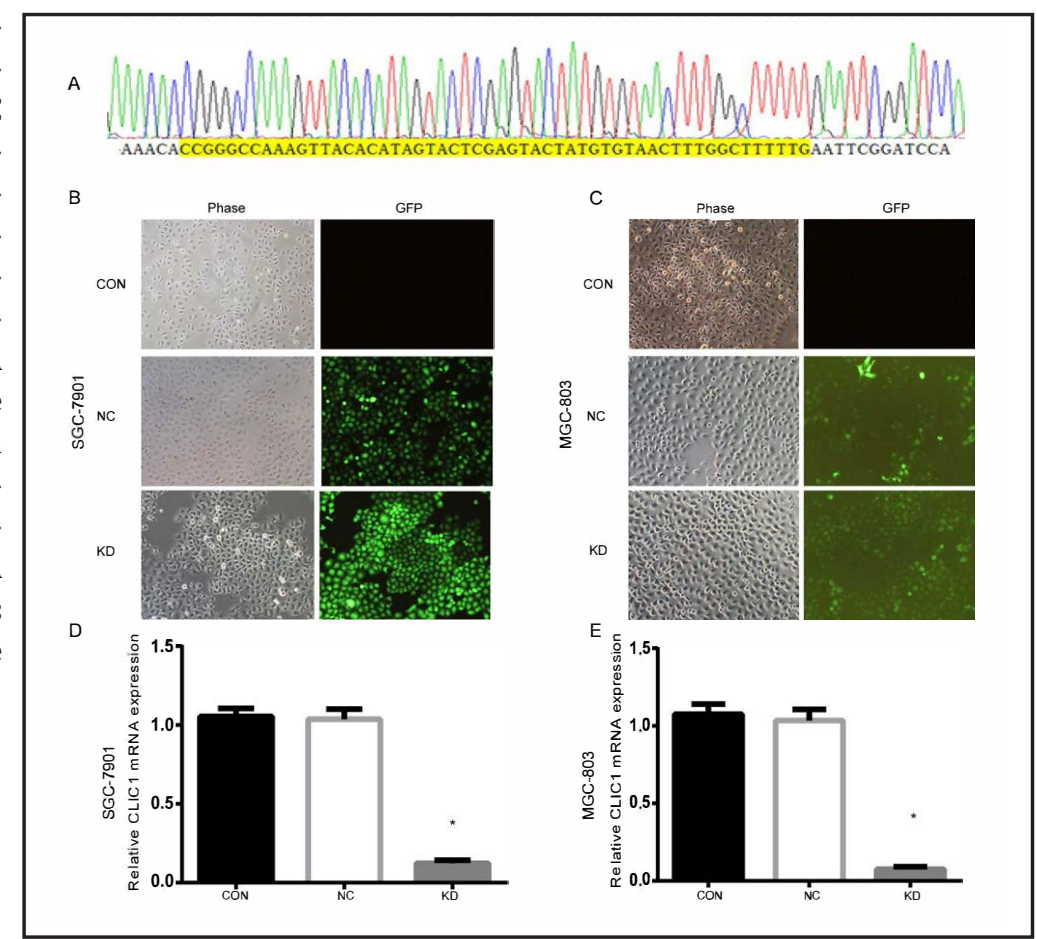

Fig. 3. Apoptosis and apoptosis-related protein expression levels in GC cells after CLIC1 silencing. FCM showed that the apoptosis rate of SGC-7901 and MGC-803 cells increased significantly after CLIC1 silencing $\left({ }^{*} P<0.05\right.$ vs blank control and negative control groups) (A-C). The CLIC1 and Bcl-2 expression levels were significantly suppressed $\left({ }^{*} P<0.05\right.$ vs blank control and negative control groups), while the survivin expression level remained unchanged $\quad{ }^{*} P>0.05 \quad$ vs blank control and negative control groups) in SGC-7901 and MGC-803 cells after CLIC1 silencing (D-E).

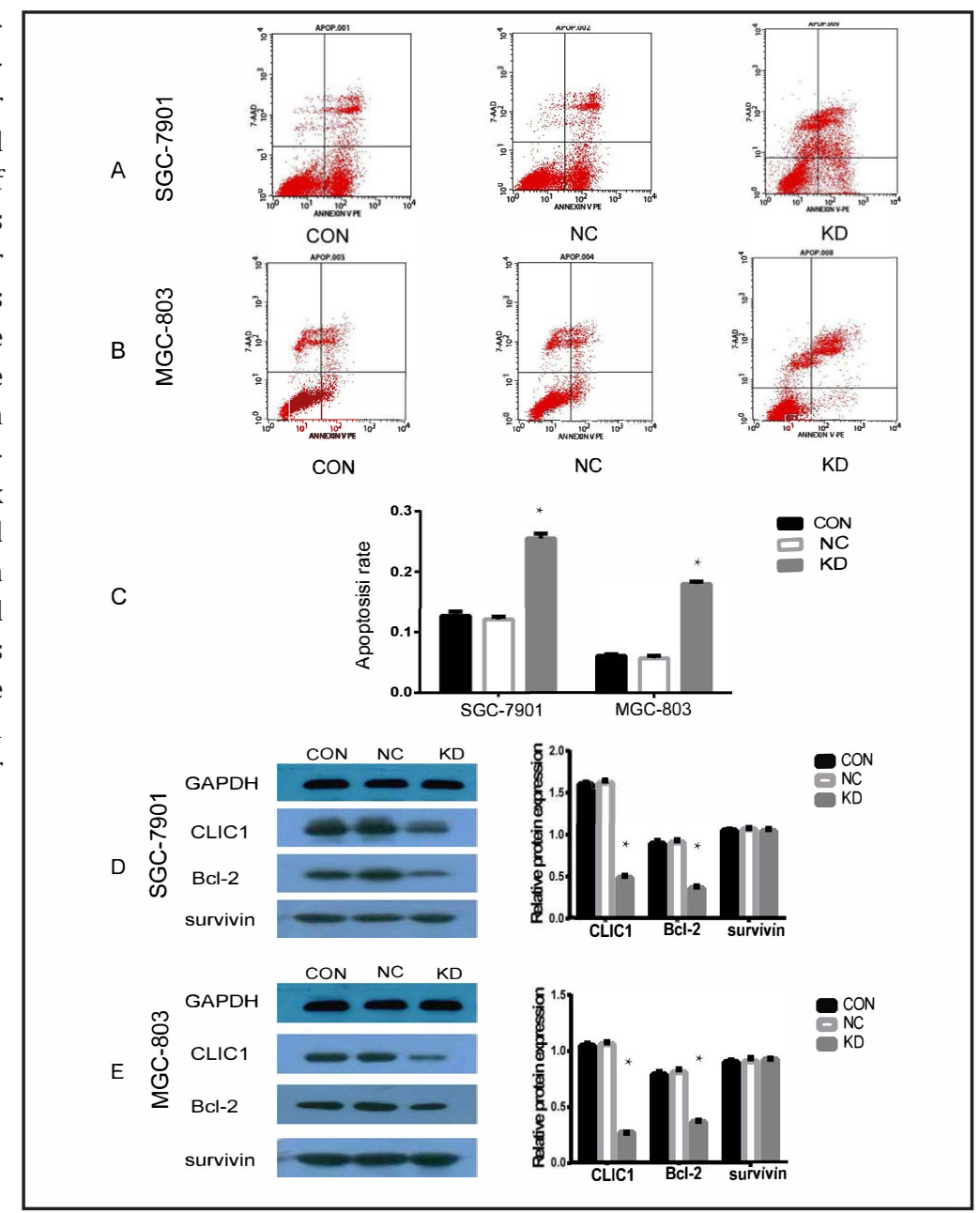


and 3). Then, we submitted integrin genes, CLIC1 and MAPK family genes into geneMANIA (http://genemania.org/) for signal pathway prediction to explore whether CLIC1 is associated with integrins and the MAPK signaling pathway. The results showed thatCLIC1, ITG $\alpha$, ITG $\alpha 1$, ITG $\alpha 3$, ITG $\beta 1$, EKR, AKT1 and p38 are in the same signal network (Fig.5), which suggests there may be regulatory relationships among them. We performed protein mass spectrometry analysis in one of the GC cell lines, and the above hypothesis was confirmed in the following experiments in both of the SGC-7901 and MGC-803 cell lines.

\section{CLIC1 silencing affected the expressions of ITGs}

Our study showed that the CLIC1 mRNA expression was significantly inhibited in both KD groups of SGC-7901 and MGC-803 cells $(P<0.05)$. CLIC1 silencing significantly increased ITG $\alpha 1$ mRNA expression, but inhibited the expression of ITG $\alpha 3$, ITG $\alpha v$ and ITG $\beta 1$ mRNA $(P<0.05)$ (Fig. 6A-B). Western blot assays also displayed similar findings (Fig. 6C-D).

\section{CLIC1 silencing inhibited the subcutaneous tumor growth of GC}

The subcutaneous tumors of the original generation were successfully constructed in the SGC-7901,SGC-7901-NC,SGC-7901-KD,MGC-803 and MGC-803-NC groups in about 2-3 weeks in BALB/C nude mice, but failed in the MGC-803-KD group (Fig. 7A-B).The subcutaneous tumor growth of the original generation of the SGC-7901-KD group was significantly inhibited after CLIC1 silencing $(P<0.05)$ (Fig. 7A).Finally, the CLIC1 silencing group (MGC-803-chol) and its negative control group (MGC-803-NC1) were successfully established as subcutaneous tumors of the original generation after using siRNA by special chemical modification (chol-siRNA).We found that the tumor growth of the MGC-803-chol group was slower than the MGC-803-NC1 group $(P<0.05)$ (Fig. 7C). Compared with the corresponding control group, the subcutaneous tumor growth of second generation was significantly inhibited in the SGC-7901-KD and the MGC-803-chol groups $(P<0.05)$ (Fig. 7D-E). After HE staining, the subcutaneous tumor tissues that had cells with irregular arrangements, varied sizes, large nuclei that were deeply stained, an increased nucleoplasm ratio, obvious nuclear atypia and pathologic mitosis were verified as GC cells (Fig. 7F-G).

Table 2. The up-regulated expression proteins of SGC-7901 after CLIC1 interference in the Human database

\begin{tabular}{|c|c|c|c|c|c|c|c|c|c|c|c|c|}
\hline Accession & Description & Score & Coverage & \# Proteins & $\begin{array}{l}\text { \# Unique } \\
\text { Peptides }\end{array}$ & $\begin{array}{c}\# \\
\text { Peptides }\end{array}$ & $\begin{array}{c}\# \\
\text { PSMs }\end{array}$ & $114 / 115$ & $\begin{array}{c}114 / 115 \\
\text { Count }\end{array}$ & $\begin{array}{c}\# \\
\text { AAs }\end{array}$ & $\begin{array}{c}\text { MW } \\
{[\mathrm{kDa}]}\end{array}$ & calc. pI \\
\hline B4E0X7 & Zinc finger protein 512 & 1.63 & 1.82 & 5 & 1 & 1 & 1 & 0.125 & 1 & 385 & 44.1 & 9.82 \\
\hline P48775 & Tryptophan 2,3-dioxygenase & 0.00 & 2.46 & 1 & 1 & 1 & 1 & 0.145 & 1 & 406 & 47.8 & 6.93 \\
\hline Q01970-2 & Isoform 2 of 1-phosphatidylinositol 4,5- & 1.68 & 0.69 & 2 & 1 & 1 & 1 & 0.198 & 1 & 1167 & 131.1 & 5.88 \\
\hline Q8WXE9 & Stonin-2 & 1.90 & 0.99 & 2 & 1 & 1 & 1 & 0.204 & 1 & 905 & 101.1 & 5.39 \\
\hline HOYGE4 & Protein LOC728763 (Fragment) & 1.73 & 4.10 & 2 & 1 & 1 & 1 & 0.249 & 1 & 268 & 30.2 & 6.62 \\
\hline Q9Y277 & Voltage-dependent anion-selective channel & 4.62 & 6.36 & 3 & 1 & 2 & 3 & 0.282 & 1 & 283 & 30.6 & 8.66 \\
\hline P11274-2 & Isoform 2 of Breakpoint cluster region & 0.00 & 0.90 & 2 & 1 & 1 & 1 & 0.287 & 1 & 1227 & 137.6 & 7.21 \\
\hline J3QR09 & Ribosomal protein L19 & 1.78 & 4.66 & 3 & 1 & 1 & 1 & 0.316 & 1 & 193 & 23.1 & 11.47 \\
\hline C9JNP9 & Ubiquitin fusion degradation protein 1 & 1.85 & 5.03 & 6 & 1 & 1 & 1 & 0.342 & 1 & 159 & 17.5 & 4.75 \\
\hline P49207 & 60 S ribosomal protein $\mathrm{L} 34$ & 0.00 & 7.69 & 1 & 1 & 1 & 1 & 0.351 & 1 & 117 & 13.3 & 11.47 \\
\hline F8W720 & GMP synthase [glutamine-hydrolyzing] & 7.82 & 8.92 & 2 & 4 & 4 & 5 & 0.362 & 4 & 594 & 65.9 & 7.47 \\
\hline J3QR71 & Developmentally-regulated GTP-binding & 0.00 & 12.66 & 5 & 1 & 1 & 1 & 0.364 & 1 & 158 & 16.9 & 9.06 \\
\hline A6NP16 & Angiomotin & 0.00 & 2.35 & 6 & 1 & 1 & 2 & 0.366 & 2 & 597 & 68.4 & 8.06 \\
\hline P18124 & $60 \mathrm{~S}$ ribosomal protein $\mathrm{L} 7$ & 15.51 & 27.02 & 3 & 8 & 8 & 17 & 0.374 & 13 & 248 & 29.2 & 10.65 \\
\hline HOYHD8 & Cysteine-rich protein 2 (Fragment) & 0.00 & 18.27 & 4 & 1 & 1 & 1 & 0.375 & 1 & 104 & 11.2 & 8.38 \\
\hline P42765 & 3-ketoacyl-CoA thiolase, mitochondrial & 1.95 & 2.77 & 1 & 1 & 1 & 1 & 0.386 & 1 & 397 & 41.9 & 8.09 \\
\hline Q14160 & Protein scribble homolog & 0.00 & 0.61 & 2 & 1 & 1 & 1 & 0.387 & 1 & 1630 & 174.8 & 5.07 \\
\hline E9PLH9 & GDP-L-fucose synthase (Fragment) & 2.06 & 9.24 & 4 & 1 & 1 & 1 & 0.389 & 1 & 119 & 12.9 & 8.03 \\
\hline F8VWC5 & $60 \mathrm{~S}$ ribosomal protein L18 & 4.03 & 29.56 & 7 & 4 & 4 & 11 & 0.403 & 8 & 159 & 18.1 & 11.84 \\
\hline E7EPB3 & 60 S ribosomal protein L14 & 1.69 & 9.68 & 2 & 1 & 1 & 2 & 0.404 & 2 & 124 & 14.5 & 10.21 \\
\hline P61254 & 60 S ribosomal protein L26 & 0.00 & 5.52 & 1 & 1 & 1 & 2 & 0.404 & 2 & 145 & 17.2 & 10.55 \\
\hline P43490 & Nicotinamide phosphoribosyltransferase & 5.10 & 14.87 & 2 & 5 & 5 & 5 & 0.414 & 5 & 491 & 55.5 & 7.15 \\
\hline Q5T7N2 & LINE-1 type transposase domain- & 2.31 & 0.92 & 1 & 1 & 1 & 2 & 0.425 & 1 & 865 & 98.8 & 4.93 \\
\hline P50238 & Cysteine-rich protein 1 & 0.00 & 20.78 & 3 & 2 & 2 & 4 & 0.432 & 4 & 77 & 8.5 & 8.75 \\
\hline P56199 & Integrin alpha-1 & 1.77 & 0.76 & 1 & 1 & 1 & 1 & 0.446 & 1 & 1179 & 130.8 & 6.29 \\
\hline Q9Y3U8 & 60 S ribosomal protein $\mathrm{L} 36$ & 1.78 & 10.48 & 1 & 1 & 1 & 1 & 0.451 & 1 & 105 & 12.2 & 11.59 \\
\hline P07741-2 & Isoform 2 of Adenine & 4.03 & 32.84 & 6 & 4 & 4 & 6 & 0.455 & 5 & 134 & 14.5 & 7.34 \\
\hline C9J8U2 & Nicotinate phosphoribosyltransferase & 11.19 & 14.69 & 6 & 6 & 6 & 10 & 0.459 & 8 & 490 & 52.1 & 5.33 \\
\hline P31942-6 & Isoform 6 of Heterogeneous nuclear & 2.47 & 7.19 & 7 & 1 & 1 & 1 & 0.464 & 1 & 139 & 15.4 & 6.40 \\
\hline P16152 & Carbonyl reductase [NADPH] 1 & 5.65 & 40.43 & 5 & 8 & 8 & 12 & 0.470 & 10 & 277 & 30.4 & 8.32 \\
\hline P36578 & $60 \mathrm{~S}$ ribosomal protein $\mathrm{L} 4$ & 4.07 & 10.30 & 4 & 4 & 4 & 12 & 0.475 & 12 & 427 & 47.7 & 11.06 \\
\hline P49411 & Elongation factor Tu, mitochondrial & 3.61 & 15.71 & 1 & 5 & 5 & 5 & 0.479 & 5 & 452 & 49.5 & 7.61 \\
\hline P09874 & Poly [ADP-ribose] polymerase 1 & 0.00 & 0.69 & 1 & 1 & 1 & 1 & 0.489 & 1 & 1014 & 113.0 & 8.88 \\
\hline E9PN89 & Heat shock cognate $71 \mathrm{kDa}$ protein & 148.16 & 57.69 & 1 & 1 & 18 & 128 & 0.489 & 1 & 312 & 34.8 & 7.53 \\
\hline $\mathrm{P} 63173$ & $60 \mathrm{~S}$ ribosomal protein L38 & 0.00 & 14.29 & 1 & 1 & 1 & 1 & 0.495 & 1 & 70 & 8.2 & 10.10 \\
\hline
\end{tabular}


Table 3. The down-regulated expression proteins of SGC-7901 after CLIC1 interference in the Human database

\begin{tabular}{|c|c|c|c|c|c|c|c|c|c|c|c|c|}
\hline Accession & Description & Score & Coverage & $\begin{array}{c}\# \\
\text { Proteins }\end{array}$ & $\begin{array}{l}\text { \# Unique } \\
\text { Peptides }\end{array}$ & $\begin{array}{c}\text { \# } \\
\text { Peptides }\end{array}$ & $\begin{array}{c}\# \\
\text { PSMs }\end{array}$ & $114 / 115$ & $\begin{array}{c}114 / 115 \\
\text { Count }\end{array}$ & $\begin{array}{c}\# \\
\text { AAs }\end{array}$ & $\begin{array}{c}\mathrm{MW} \\
\text { [kDa] }\end{array}$ & $\begin{array}{c}\text { calc. } \\
\text { pl }\end{array}$ \\
\hline A6NNI4 & CD9 antigen & 4.26 & 6.29 & 3 & 1 & 1 & 4 & 2.022 & 2 & 159 & 17.8 & 6.29 \\
\hline 075874 & Isocitrate dehydrogenase [NADP] cytoplasmic & 18.25 & 21.50 & 4 & 7 & 7 & 14 & 2.039 & 10 & 414 & 46.6 & 7.01 \\
\hline Q02539 & Histone H1.1 & 52.51 & 27.91 & 2 & 2 & 6 & 39 & 2.049 & 3 & 215 & 21.8 & 10.99 \\
\hline Q9Bт09 & Protein canopy homolog 3 & 9.40 & 12.59 & 1 & 3 & 3 & 5 & 2.136 & 5 & 278 & 30.7 & 5.49 \\
\hline Q9UNZ2-4 & Isoform 2 of NSFL1 cofactor 447 & 8.35 & 25.37 & 7 & 6 & 6 & 10 & 2.168 & 5 & 339 & 37.3 & 5.11 \\
\hline Q96P20-2 & $\begin{array}{l}\text { Isoform } 1 \text { of NACHT, LRR and PYD domains- } \\
\text { containing protein } 3\end{array}$ & 0.00 & 2.28 & 4 & 1 & 1 & 1 & 2.182 & 1 & 922 & 105.9 & 6.64 \\
\hline K7ЕMU3 & Integrin alpha-3 (Fragment) & 0.00 & 8.55 & 4 & 1 & 1 & 1 & 2.193 & 1 & 117 & 12.9 & 5.40 \\
\hline с9јҮР1 & Protein FAM107B (Fragment) & 0.00 & 17.91 & 9 & 1 & 1 & 1 & 2.218 & 1 & 67 & 8.0 & 9.47 \\
\hline Q5RKV6 & Exosome complex component MTR3 & 0.00 & 4.04 & 1 & 1 & 1 & 1 & 2.231 & 1 & 272 & 28.2 & 6.28 \\
\hline 094826 & Mitochondrial import receptor subunit TOM70 & 2.04 & 2.47 & 1 & 2 & 2 & 2 & 2.252 & 2 & 608 & 67.4 & 7.12 \\
\hline B8ZZQ6 & Thymosin alpha- 1 & 98.37 & 14.02 & 6 & 4 & 4 & 61 & 2.281 & 57 & 107 & 11.8 & 3.81 \\
\hline Q9NNW7-4 & $\begin{array}{l}\text { Isoform } 4 \text { of Thioredoxin reductase } 2 \text {, } \\
\text { mitochondrial }\end{array}$ & 2.26 & 3.97 & 9 & 1 & 1 & 1 & 2.525 & 1 & 277 & 30.3 & 6.28 \\
\hline P17096-2 & $\begin{array}{l}\text { Isoform HMG-Y of High mobility group protein } \\
\text { HMG-I/HMG-Y }\end{array}$ & 6.49 & 34.38 & 4 & 3 & 3 & 5 & 2.747 & 3 & 96 & 10.7 & 10.32 \\
\hline P12277 & Creatine kinase B-type & 31.70 & 30.18 & 6 & 9 & 9 & 21 & 2.842 & 18 & 381 & 42.6 & 5.59 \\
\hline P04264 & Keratin, type II cytoskeletal 1 & 10.93 & 9.78 & 3 & 5 & 6 & 9 & 3.007 & 5 & 644 & 66.0 & 8.12 \\
\hline F8WBE5 & Transferrin receptor protein 1 , serum form & 1.76 & 17.28 & 2 & 1 & 1 & 1 & 3.204 & 1 & 81 & 8.9 & 5.33 \\
\hline Q9H4G0-3 & Isoform 3 of Band 4.1-like protein 1 & 0.00 & 3.50 & 4 & 2 & 2 & 2 & 3.717 & 1 & 772 & 86.5 & 5.81 \\
\hline Q9Y275-2 & $\begin{array}{l}\text { Isoform } 2 \text { of Tumor necrosis factor ligand } \\
\text { superfamily member 13B }\end{array}$ & 2.03 & 3.76 & 2 & 1 & 1 & 1 & 4.452 & 1 & 266 & 29.1 & 6.90 \\
\hline
\end{tabular}

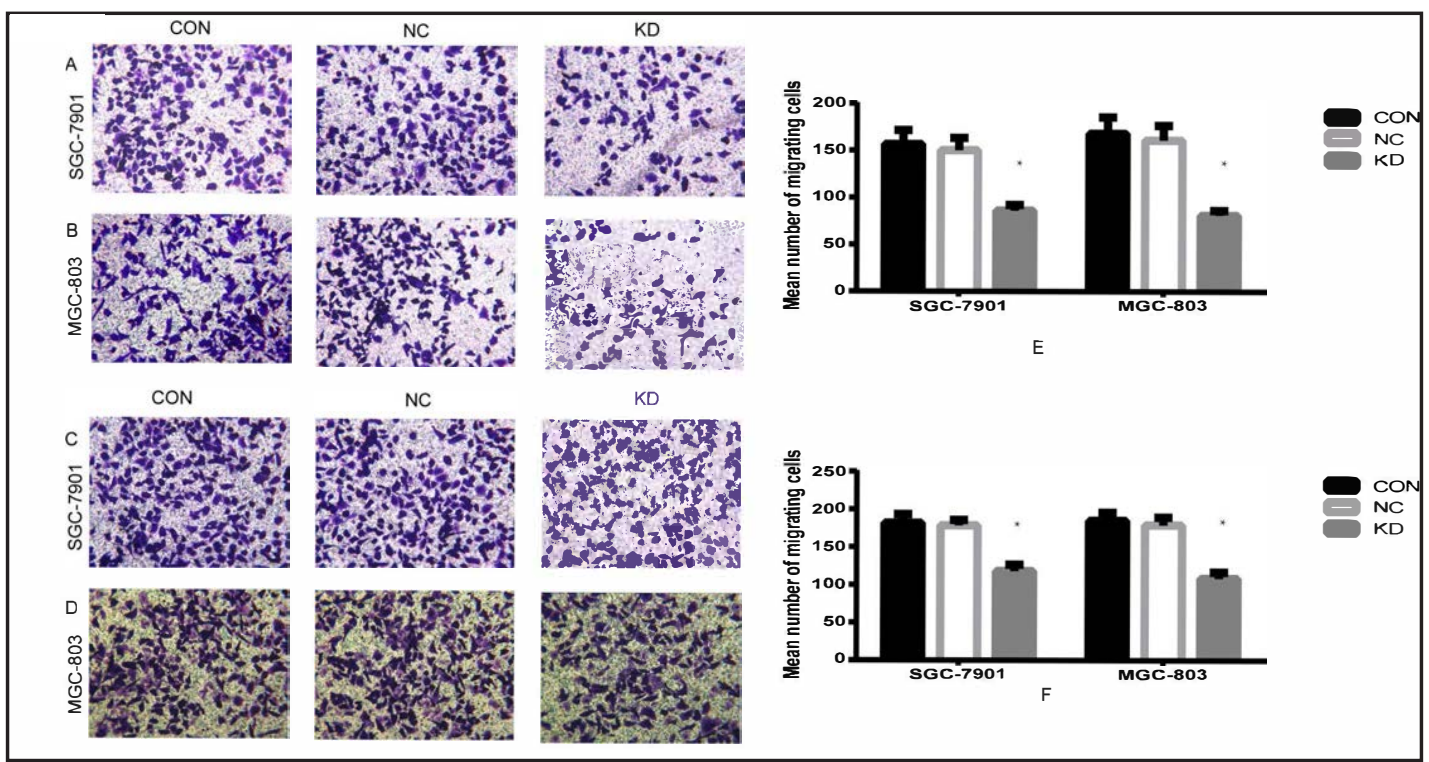

Fig. 4. Migration and invasion abilities of SGC-7901 and MGC-803 cells in vitro after CLIC1 silencing. The cell migration assay showed that the number of SGC-7901 and MGC-803 cells crossing the basement membrane significantly decreased after CLIC1-siRNA3 transfection ${ }^{*} P<0.05$ vs blank control and negative control groups). The cell invasion assay showed that the number of SGC-7901 and MGC-803 cells crossing the basement membrane markedly decreased after CLIC1-siRNA3 transfection ${ }^{*} P<0.05$ vs blank control and negative control groups).

Orthotopically transplanted GC tumors were successfully established

The mice were sacrificed after feeding for several weeks. The orthotopically transplanted GC tumors were successfully constructed, and the tumor volume and mass of theSGC-7901KD and MGC-803-chol groups were significantly lower than those of the corresponding 
control groups (Fig. 8A-F). The CLIC1 protein expression detected by WES technology was significantly reduced in the SGC-7901-KD and MGC803-chol groups (Fig. 8G-I).

CLIC1 inhibited the apoptosis of orthotopically transplanted GC tumors

The apoptosis of orthotopically transplanted GC tumors was detected using TUNEL by DAB and fluorescence staining. The apoptosis rate after CLIC1 silencing was significantly higher than that of the CON group in SGC-7901 and MGC-803 cells $(21.92 \%$ vs $2.12 \%$ and $26.50 \%$ vs $3.35 \%$, respectively, $P<0.05$ ) (Fig. 9A). When fluorescence staining was used, the apoptosis rate was similar to that measured by DAB staining $(P<0.05)$ (Fig. 9B). We further detected the

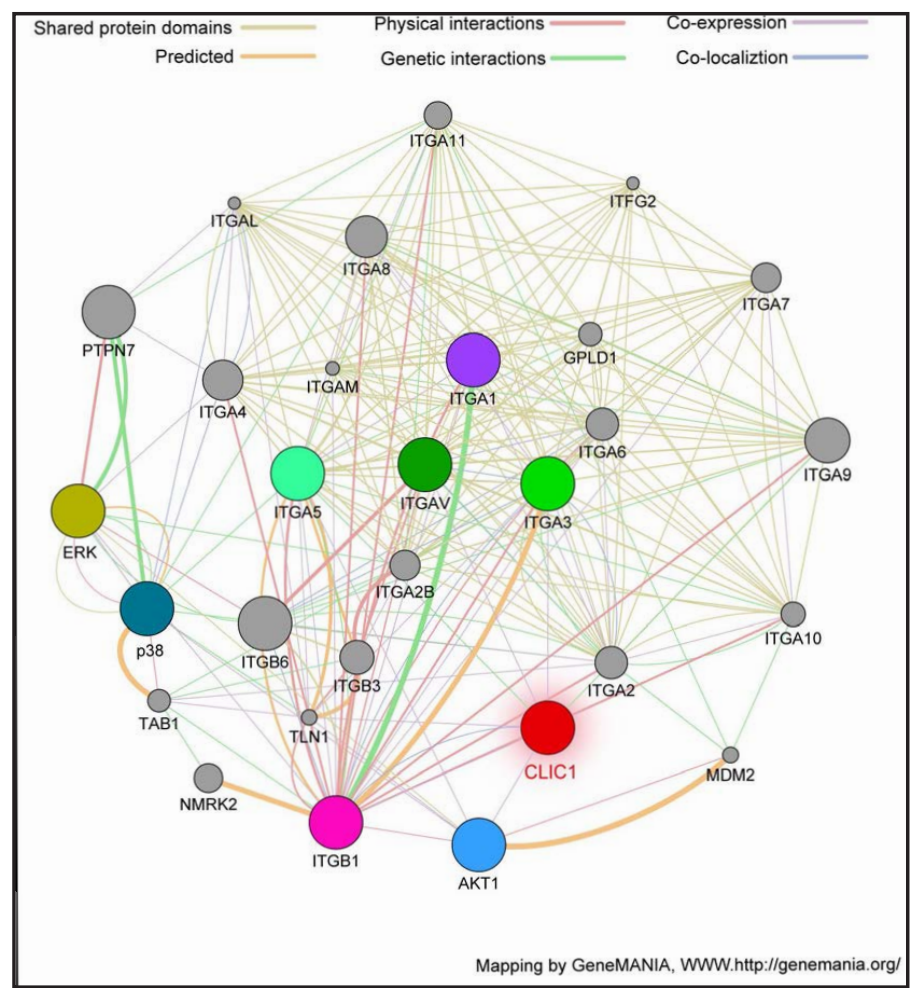

Fig. 5. The CLIC1 regulatory relationship with integrin genes and MAPK family genes by geneMANIA for signal pathway prediction.
Fig. 6. The mRNA and protein expression levels of integrinsfrom SGC-7901 and MGC803 cells in vitro after CLIC1 silencing. CLIC1 silencing significantly increasedITG $\alpha 1$ mRNA expression, but inhibited the ITG $\alpha 3$, ITG $\alpha$ vandITG $\beta 1$ mRNA expression levels $\left({ }^{*} P<0.05\right.$ vs blank control and negative control groups) in SGC-7901 and MGC-803 cells (AB). The protein expression levels were similar to the mRNA levels (D-E) $\left({ }^{*} P<0.05\right.$ vs blank control and negative control groups).
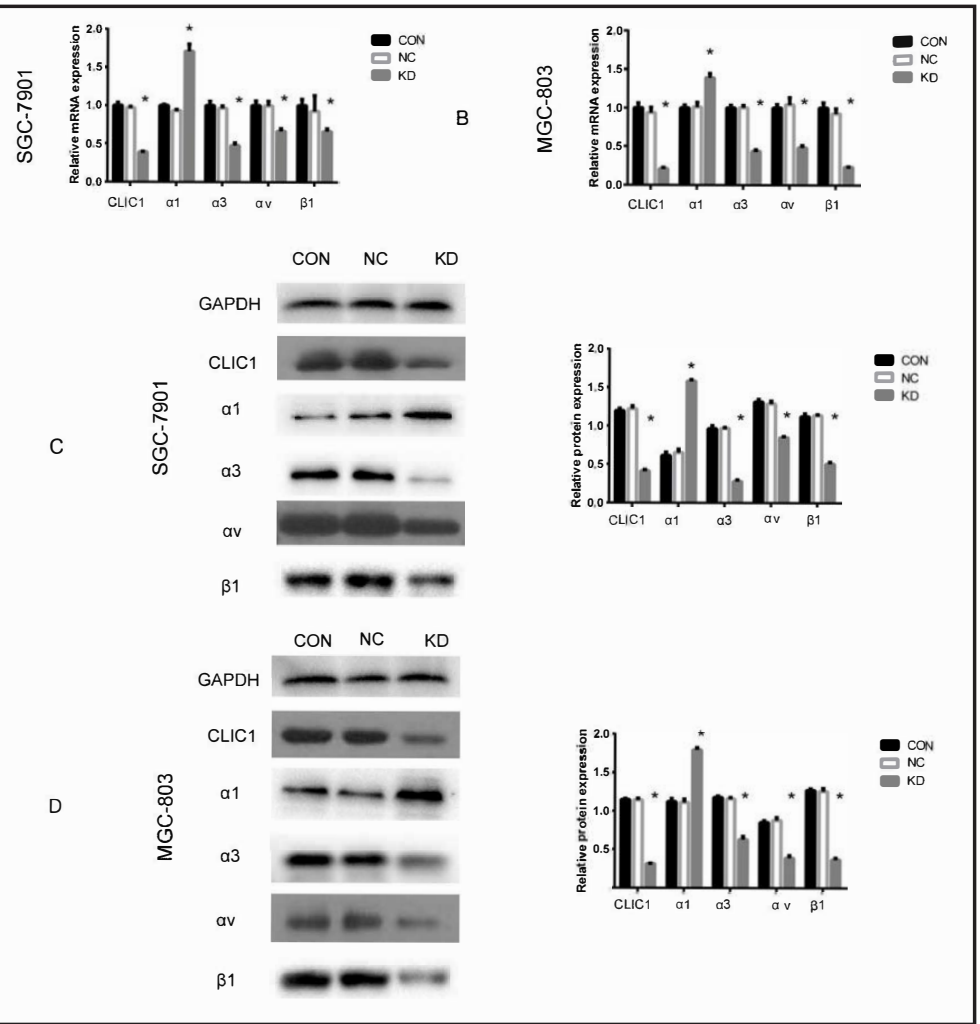
Fig. 7. The subcutaneous tumor growth of SGC-7901 and MGC-803 cells in vivo after CLIC1 silencing and histopathological results. The growth of primary subcutaneous tumors of the SGC-7901KD group was significantly inhibited $\left({ }^{*} P<0.05\right.$, knock down group vs blank control and negative control groups) (A), but the primary subcutaneous tumors of MGC-803-CLIC1-KD failed to establish (B). The growth of primary subcutaneous tumors of the MGC-803CLIC1-chol group were significantly inhibited $\left({ }^{*} P<0.05\right.$, knock down group vs corresponding negative control group) (C). The subcutaneous tumor growth of the second generation was also significantly inhibited in the SGC-7901-CLIC1KD and MGC-803-CLIC1-chol groups $\left({ }^{*} P<0.05\right)(\mathrm{D}-\mathrm{E})$. After HE staining, the subcutaneous tumor tissues of SGC7901 and MGC-803 groups were verified for GC by HE staining (400×) (F-G).

expression levels of apoptosisrelated proteins ( $\mathrm{Bcl}-2$ and $\mathrm{Bax}$ ), and the results showed that CLIC1 silencing significantly suppressed Bcl-2 and increased Bax protein expression in both SGC-7901 and MGC-803 cells $(P<0.05)$ (Fig. 9CE).

Metabolic rate of the orthotopically transplantated
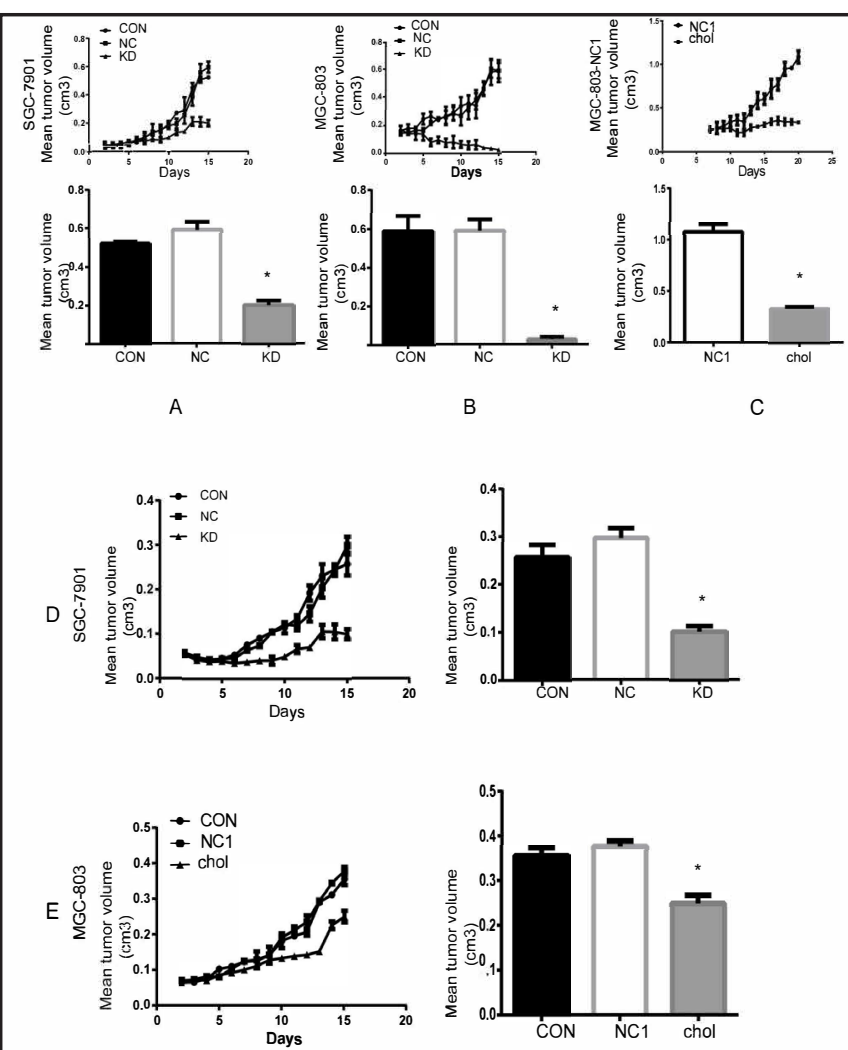

tumors was reduced after

CLIC1 silencing

Compared with the corresponding control group, PET-CT showed that the metabolic rate of the orthotopically transplanted tumors was significantly reduced in the SGC-7901-KD and MGC-803-chol groups $(P<0.05)$, but distant metastasis was not observed in any of the groups (Fig. 10A-D).

CLIC1 silencing affected the relative protein expression levels of ITGs and signaling pathways

WES technology showed that the protein expression of ITG $\alpha 1$ was increased, but ITG $\alpha 3$, ITG $\alpha 5$, ITG $\alpha v$ and ITG $\beta 1$ were down-regulated in orthotopically transplanted tumors of the SGC-7901-KD and MGC-803-chol groups after CLIC1 silencing $(P<0.05)$ (Fig. 11A-B). Moreover, down-regulating CLIC1 also affected the expression levels of signaling pathway proteins. Our results showed that the protein expression levels of p-ERK and p-AKT in orthotopically transplantated tumors from the SGC-7901-KD and MGC-803-chol groups after CLIC1 silencing were significantly lower than those of the control groups $(P<0.05)$, but the expression level of p-p38 was increased $(P<0.05)$. The expression levels of ERK, AKT and p38 were similar to those of the control groups $(P>0.05)$ (Fig. 11A\&C). 


\section{Discussion}

Our results show that $C L I C 1$ silencing promoted GC cell apoptosis and inhibited migration and invasion in vitro. Moreover, inhibiting CLIC1 affected the expression of ITGs at both the mRNA and protein levels. Furthermore, we demonstrated that in vivo CLIC1 has a similar function, as CLIC1 knockdown suppressed orthotopic xenograft tumor volume, weight, metabolism and lymphatic infiltration capacity, and promoted apoptosis. Additionally, inhibiting CLIC1 not only effectively affected the expression of protein of ITGs, but also influenced AKT and MAPK pathways in orthotopically xenografted tumors in nude mice models.

CLIC1 is an intracellular ion channel that is involved in many important physiological processes in the body [3]. At present, CLIC1 has been found to be closely related to many kinds of tumors. Several studies have shown that CLIC1 is expressed at a low level in normal gastric tissues and highly expressed in GC tissues [14-16]. It has also been found that the expression of CLIC1 in GC is closely related to the invasion and metastasis of lymph nodes and the infiltration of peripheral nerves, suggesting that CLIC1 is a potential tumor marker [7]. In this study, we successfully established a recombinant lentiviral expression vector targeting CLIC1 using RNAi, and then we established stable GC cell lines with low CLIC1 expression. The inhibition rate of CLIC1 in the GC lines SGC-7901-KD and MGC-803-KD was $89.3 \%$ and $93.8 \%$, respectively, which provides a stable vector for further study of the relationship between GC and CLIC1.

Studies have confirmed that CLIC1 is involved in the apoptosis of tumor cells. Kang et al. [17] showed that inhibiting the expression of CLIC1 in glioma stem cells promoted the apoptosis of tumor cells. Our results showed that the apoptosis rate of GC cells after knockdown of CLIC1 significantly increased, suggesting that CLIC1 silencing is able to promote the apoptosis of GC cells. In addition, we measured the expression of apoptosisrelated proteins (Bcl-2 and survivin) to elucidate the anti-apoptotic mechanisms of CLIC1 in each group. Notably, the expression levels of these two proteins were the same after CLIC1 silencing. In the silenced groups, $\mathrm{Bcl}-2$ expression decreased while survivin expression remained unchanged.

Migration and invasion are the basic processes of metastasis in malignant tumor cells. Reports have shown that CLIC1 silencing significantly decreased the migration and invasion of 
Fig. 9. The apoptosis of orthotopically transplanted tumors of GC and the expression levels of apoptosis proteins. The apoptosis of orthotopically transplanted GC tumors in both the SGC7901-KD and MGC-803-chol groups were higher than those of the control group $\left({ }^{*} \mathrm{P}<0.05\right)$ (A-B). CLIC1 silencing significantly suppressed Bcl2 and increased Bax protein expression levels in both SGC-7901 and MGC-803 cells $\left({ }^{*} \mathrm{P}<0.05\right)(\mathrm{C}-\mathrm{E})$.

colon cancer and prostate cancer cells $[5,6]$, while CLIC1 over-expression markedly increased the migration and invasion of hepatocellular carcinoma cells [18]. Our results show that the migration

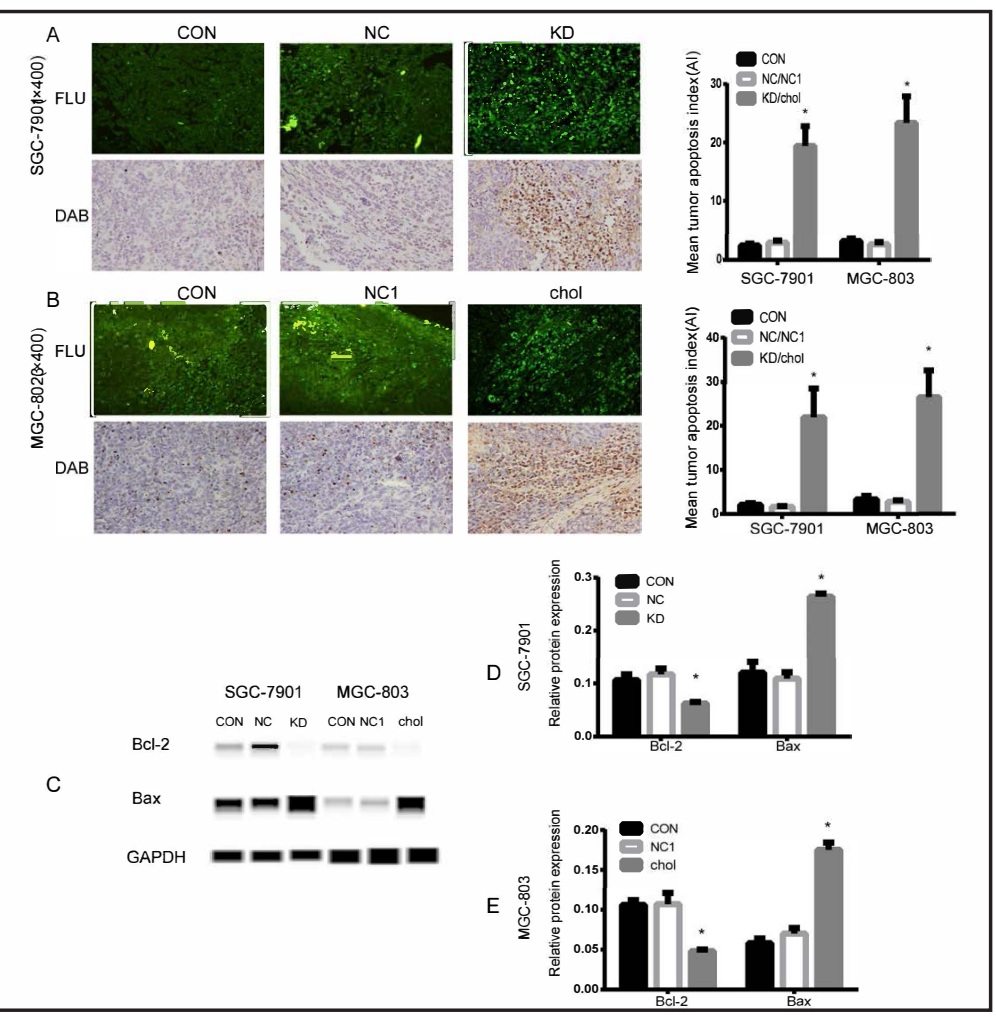
and invasion of SGC7901KD and MGC-803KD cells significantly decreased after inhibition of CLIC1 expression, which is consistent with the results of previous studies.

The mechanism of how CLIC1 is involved in apoptosis, invasion and metastasis of GC cells remains unclear. ITGs play an important role in the apoptosis, invasion and metastasis of GC $[19,20]$. It is possible that CLIC1 interacts with ITGs to regulate the progression of GC. In order to verify this hypothesis, we used iTRAQ technology to analyze the differentially expressed proteins of SGC-7901 GC cells before and after inhibiting the expression of CLIC1 [21]. We found that ITGs were differentially expressed, and verification experiments showed that

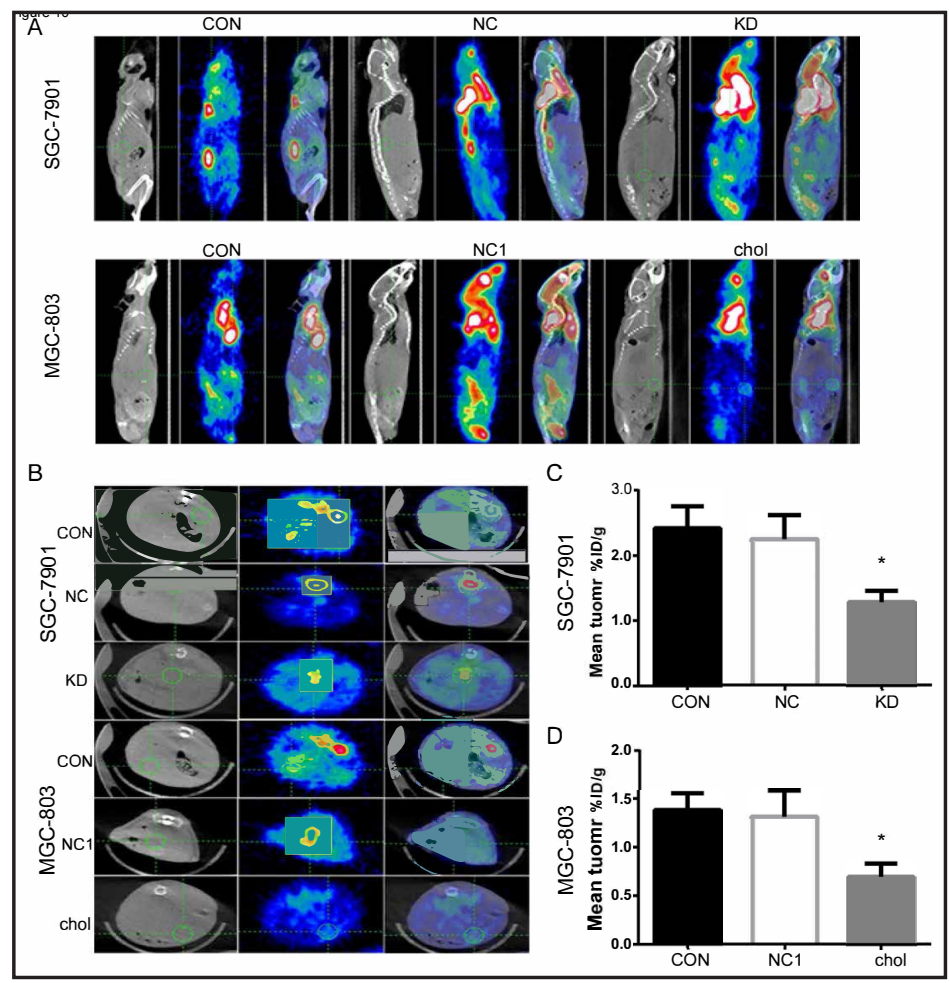

Fig. 10. The metabolic rate of primary orthotopically transplanted tumors by PET-CT. The metabolic rate of primary orthotopically transplanted tumors after CLIC1 silencing was significantly reduced in both the SGC-7901 and MGC-803 groups $\left({ }^{*} P<0.05\right)(A-D)$. 
the expression of ITG $\alpha 3$, ITG $\alpha$ v and ITG $\beta 1$ in the two GC cell lines were downregulated at both the mRNA and protein level, but the expression of ITG $\alpha 1$ was up-regulated. Other studies have investigated the level of ITGs in various tumors. Tanaka and Fukuzawa [22] found that the invasiveness of human neuroblastoma cells was inhibited by up-regulating ITG $\alpha 1$. Additionally, Nakada et al. [23] reported that ITG $\alpha 3$ is over-expressed in glioma stem-like cells and promotes invasion. Furthermore, evidence shows that overexpression of ITGav is closely associated with the metastasis and progression of some cancers [24, 25].

Specifically, Yim et al. [26] showed that ITG $\alpha 1$ was significantly associated with the occurrence of GC. In addition, Fukuda et al. [20] found that ITG $\alpha 1$ was highly expressed in GC cells, and using a specific blocking agent, the adhesion of GC cells decreased significantly. In this study, we found that ITG $\alpha 1$ was over-expressed, and migration and invasion was inhibited, results that are corroborated by the findings of Fukuda et al.

Studies have found that

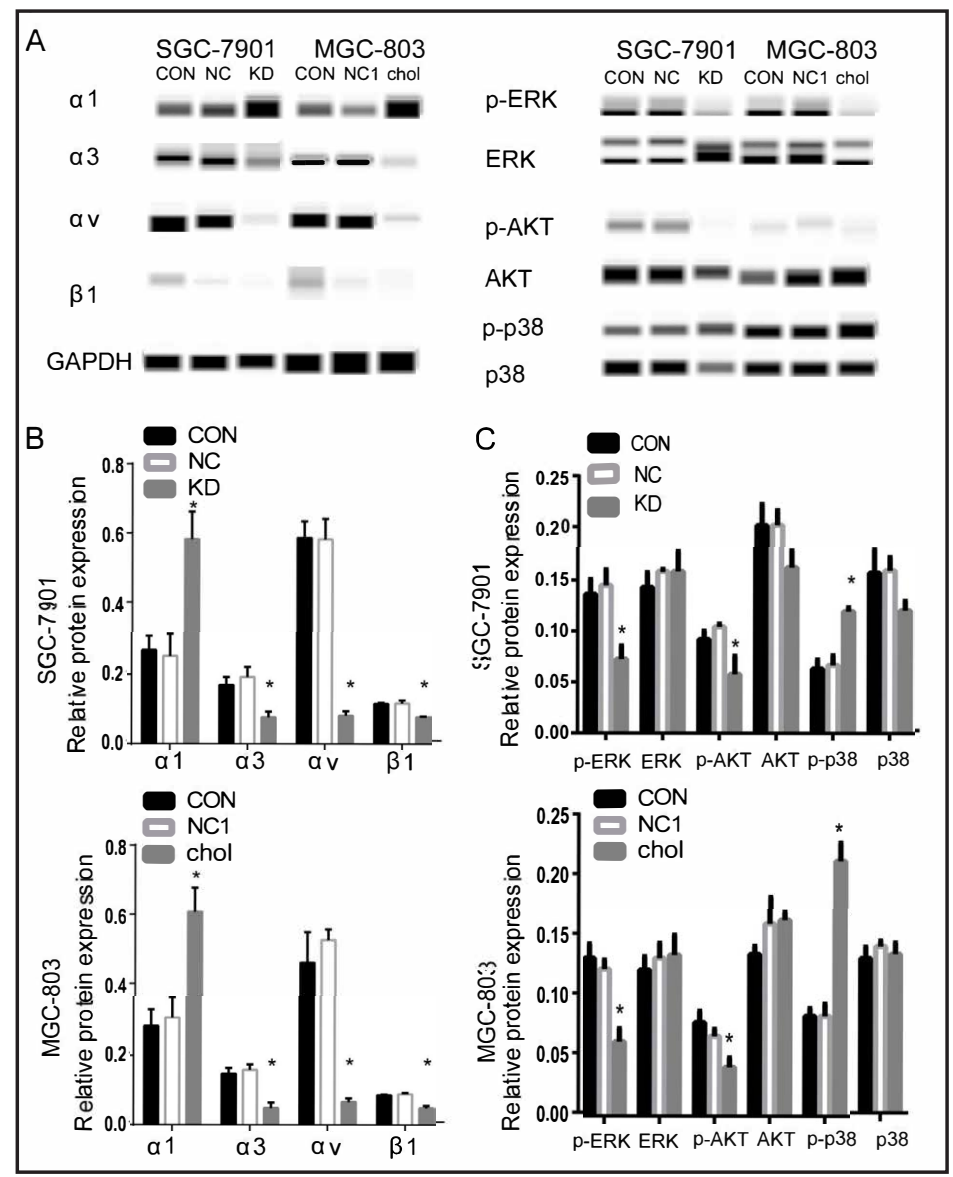

Fig. 11. The relative protein expression levels of integrins and signaling pathways after CLIC1 silencing in vivo by WES technology. In the SGC-7901 and MGC-803 groups, the protein expression of ITG $\alpha 1$ was increased, but the integrins ITG $\alpha 3$, ITG $\alpha 5$, ITG $\alpha$ v and ITG $\beta 1$ were down-regulated in orthotopically transplanted tumors after CLIC1 silencing $\left({ }^{*} P<0.05\right)(\mathrm{A}-\mathrm{B})$. In the SGC-7901 and MGC-803 groups, the protein expression levels of p-ERK and p-AKT in orthotopically transplanted tumors after CLIC1 silencing were significantly lower than those of the control groups, but p-p38 was increased $\left({ }^{*} P<0.05\right)$ and the ERK, AKT and p38 levels were similar to those of the control groups $(P>0.05)$ (A and $C)$.

ITG $\alpha 3$ is an important component of the receptors of the basement membrane, which is also involved in the reorganization of the cytoskeleton, and mediates the movement of GC cells to distant metastasis. Moreover, there is a positive correlation between ITG $\alpha 3$ and tumor TNM stage and lymph node metastasis [27]. Combined with the down-regulation of ITG $\alpha 3$ in our study, GC cells appear to infiltrate the basement membrane and degrade the extracellular matrix, leading to the inhibition of distant metastasis, which is consistent with our results. ITG $\alpha$ v is over-expressed in human GC tissue and is associated with the five year survival rate of GC patients [28]. Additionally, studies have indicated that ITG $\alpha$ v affects lymph node metastasis and the formation of MMP-9, which could directly provide the driving force for cell migration, especially the migration of cancer cells through endocytosis exocytosis cycle [29, 30]. Combined with the down-regulation of ITG $\alpha$ v in our study, we speculate that this could lead to the decrease in invasion and metastasis of GC cells. ITG $\beta 1$ may be an independent prognostic factor for GC patients. It promotes angiogenesis, lymph node metastasis and 
vascular invasion, which often indicates poor prognosis [31]. Inhibition of the expression of ITG $\beta 1$ inhibited the peritoneal metastasis of GC cells [32]. In the present study, the downregulation of ITG $\beta 1$ was accompanied with a decreased in the metastasis of GC cells, similar to the aforementioned findings. Thus, CLIC1 gene silencing affects the progression of GC cells in vitro by regulating the expression of ITG $\alpha 1$, ITG $\alpha 3$, ITG $\alpha$ v and ITG $\beta 1$.

Our in vitro results showing the effect of CLIC1 in GC cell lines prompted us to create an in vivo model of subcutaneous GC growth in BALB/c mice. We found that CLIC1 knockdown suppressed orthotopic xenograft tumor volume, weight, metabolism and lymphatic infiltration capacity, but promoted apoptosis. Given that GC metastasis is the leading cause of GC related death, our observations may lead to important clinical developments. The effectiveness of CLIC1 in vitro has been described predominantly in cell lines, and these results are supported by Setti et al. [6,17,33]. Our data demonstrates the effectiveness of CLIC1 in clinically relevant GC models. However, the mechanism of how CLIC1 affects apoptosis, metabolism and metastasis in GC is not clear.

Based on the observation that CLIC1 promoted the apoptosis of human GC cells accompanied by down-regulation of the apoptotic protein BCL-2, we detected the expression levels of Bcl-2 and Bax in orthotopic xenograft tumor tissue. Bax is a homologous protein of $\mathrm{Bcl}-2$, which promotes apoptosis. Bax and $\mathrm{Bcl}-2$ can form an apoptotic regulatory system [34]. The results showed that Bcl-2 is down-regulated and Bax is up-regulated. Additionally, the inhibitory effect of CLIC1 on ITGs has been described in GC cell lines in vitro, and our research shows that ITG $\alpha 3$, ITG $\alpha$ v and ITG $\beta 1$ were down-regulated, but ITG $\alpha 1$ was upregulated, consistent with what we observed in vitro. Hence, CLIC1 acts as a regulator of ITGs. On the other hand, ITGs may influence MAPK and AKT signaling in tumors [35-37]. Thus, we measured the expression of PI3K/Akt, MAPK/ERK, MAPK/p38 and MAPK/JNK in orthotopically xenografted tumors. The results showed that p-AKT and p-ERK were downregulated, p-p38 was up-regulated and p-JNK was not expressed. Therefore, we propose the following as the molecular mechanism of CLIC1 regulation. First, the formation of a Bax homodimer (Bax-Bax) induces cell apoptosis, and when Bcl-2 is highly expressed, the more stable heterodimer (Bcl-2-Bax) is formed, which suppresses apoptosis. According to our results, with the silencing of CLIC1, Bax was overexpressed, while Bcl-2 was downregulated in orthotopically transplanted tumors. We observed that relatively more Bax-Bax homodimers induced apoptosis. The phosphorylation of ERK is crucial for the activation of the MAPK/ERK pathway, and it was associated with apoptosis, metastasis of tumors [38, 39]. On the other hand, the phosphorylation of AKT is also crucial for the activation of the PI3K/AKT pathway, and it was associated with apoptosis, angiogenesis of tumors [40, 41]. We observed that CLIC1 blocked ERK-phosphorylation and AKT-phosphorylation, and both had reduced levels in orthotopically xenografted tumors. Studies have shown that ITG $\alpha$ v may be involved in the regulation of the MAPK/ERK and PI3K/AKT pathways, affecting tumor apoptosis and metastasis [40, 42]. In our study, the expression of ITG $\alpha$ v was downregulated, while at the same time, ERK-phosphorylation and AKT-phosphorylation were down-regulated after silencing CLIC1. This suggests that interference with the MAPK/ERK and PI3K/AKT pathways might be responsible for the pro-apoptotic and metastatic effects of CLIC1 induced by ITG $\alpha$ v in orthotopically xenografted GC tumors. In addition, ITG $\alpha 3$ was over-expressed in glioma stem-like cells and promoted invasion via MAPK/ERK [23]. The MAPK/p38 pathway is mainly associated with inflammation, stress and apoptosis, which are involved in the occurrence and development of GC by p38-phosphorylation activation in gastric epithelial cells $[43,44]$. When the level of p38 phosphorylation is increased, the apoptosis of GC cells increases [45]. In our study, p38-phosphorylation was increased, and the apoptosis of orthotopically xenografted tumors also increased.

There are some limitations to our study, which we plan to address in the future. First, we only used iTRAQ to screen the differential proteomics of the SGC-7901 GC cell line. Second, the mechanism of the interaction between CLIC1 and ITGs protein family is unclear. 


\section{Conclusion}

Our finds showed that siRNA-mediated down-regulation of CLIC1 expression can effectively inhibit the migration and invasion of GC in vitro and in vivo, promote apoptosis and alter the expression ITG family proteins (including ITG $\alpha 1$, ITG $\alpha 3$, ITG $\alpha$ v and ITG $\beta 1$ ) to different extents. Additionally, it regulates signaling pathway cascades. Thus, CLIC1 may play an important role in the progression of GC, and its mechanism may affect the expression of ITG family proteins, which leads to the subsequent regulation of the PI3K/AKT, MAPK/ERK and MAPK/p38 pathways.

\section{Abbreviations}

CLIC1 (Chloride intracellular channel 1); GC (Gastric cancer); RNAi (RNA interference); iTRAQ (isobaric tag for relative and absolute quantitation); ERK (extracellular regulated MAP kinase); p-ERK (phosphorylated extracellular regulated MAP kinase); AKT (AKT serine/ threonine kinase); p38 (p38 kinase); WES (Protein Simple Wes).

\section{Acknowledgements}

The study was supported by National Natural Science Foundation of China (N0.81360370); The Scientific Research and Technology-development Program of Guangxi(NO.1598011-4); The Scientific Research Project of Guangxi Zhuang Autonomous Region People's Government(NO.2014396); The Natural Science Foundation of Guangxi (2016GXNSFAA380180). The Research Project of Guangxi Health and Family Planning Commission (NO.Z2015526). The Science Foundation for Young Scientists of Guangxi Medical University (NO. GXMUYSF201502).

Jinlu Liu, Junqiang Chen designed this manuscript. Bopei Li, Yuantian Mao, Zhen Wang, Yeyang Chen, Ye Wang, Chongyu Zhai, Bo Shi, Siyu Liu, and Junqiang Chen conducted the study, collected the data, and analyzed the data. Bopei Li wrote this manuscript.

This study was approved by the Ethical Review Committee of the First Affiliated Hospital of Guangxi Medical University. Written informed consent was obtained from all patients.

\section{Disclosure Statement}

No conflict of interests exists.

\section{References}

1 Ferlay J, Soerjomataram I, Dikshit R, Eser S, Mathers C, Rebelo M, Parkin DM, Forman D, Bray F: Cancer incidence and mortality worldwide: sources, methods and major patterns in GLOBOCAN 2012. Int J Cancer 2015;136:E359-386.

2 Wang P, Zhang C, Yu P, Tang B, Liu T, Cui H, Xu J: Regulation of colon cancer cell migration and invasion by CLIC1-mediated RVD. Mol Cell Biochem 2012;365:313-321.

-3 Peretti M, Angelini M, Savalli N, Florio T, Yuspa SH, Mazzanti M: Chloride channels in cancer: Focus on chloride intracellular channel 1 and 4 (CLIC1 AND CLIC4) proteins in tumor development and as novel therapeutic targets. Biochim Biophys Acta 2015;1848:2523-2531.

4 Zhang J, Li M, Song M, Chen W, Mao J, Song L, Wei Y, Huang Y, Tang J: Clic1 plays a role in mouse hepatocarcinoma via modulating Annexin A7 and Gelsolin in vitro and in vivo. Biomed Pharmacother 2015;69:416-419.

-5 Tian Y, Guan Y, Jia Y, Meng Q, Yang J: Chloride intracellular channel 1 regulates prostate cancer cell proliferation and migration through the MAPK/ERK pathway. Cancer Biother Radiopharm 2014;29:339344.

6 Wang P, Zeng Y, Liu T, Zhang C, Yu PW, Hao YX, Luo HX, Liu G: Chloride intracellular channel 1 regulates colon cancer cell migration and invasion through ROS/ERK pathway. World J Gastroenterol 2014;20:20712078. 


\section{Cellular Physiology Cell Physiol Biochem 2018;46:907-924 \begin{tabular}{l|l} 
and Biochemistry & $\begin{array}{l}\text { DOI: 10.1159/000488822 } 2018 \\
\text { Publish } 2018 \text { The Author(s). Published by S. Karger AG, Basel } \\
\text { www.karger.com/cpb }\end{array}$
\end{tabular}

Li et al.: CLIC1 Promotes the Progression of Gastric Cancer

7 Chen C, Wang C, Huang Y, Chien K, Liang Y, Wj, Lin K: Overexpression of CLIC1 in human gastric carcinoma and its clinicopathological significance. Proteomics 2007;7:155-167.

-8 Zheng DL, Huang QL, Zhou F, Huang QJ, Lin JY, Lin X: PA28beta regulates cell invasion of gastric cancer via modulating the expression of chloride intracellular channel 1. J Cell Biochem 2012;113:1537-1546.

-9 Meng Q, Hou L, Zhao Y, Huang X, Huang Y, Xia S, Gu W, Wang W: iTRAQ-based proteomic study of the effects of Spiroplasma eriocheiris on Chinese mitten crab Eriocheir sinensis hemocytes. Fish Shellfish Immunol 2014;40:182-189.

10 Chen H, Xu L, Yin L, Xu Y, Han X, Qi Y, Zhao Y, Liu K, Peng J: iTRAQ-based proteomic analysis of dioscin on human HCT-116 colon cancer cells. Proteomics 2014;14:51-73.

11 Hou J, Lin L, Zhou W, Wang Z, Ding G, Dong Q, Qin L, Wu X, Zheng Y, Yang Y, Tian W, Zhang Q, Wang C, Zhang Q, Zhuang SM, Zheng L, Liang A, Tao W, Cao X: Identification of miRNomes in human liver and hepatocellular carcinoma reveals miR-199a/b-3p as therapeutic target for hepatocellular carcinoma. Cancer Cell 2011;19:232-243.

12 Ridnour LA, Cheng RY, Weiss JM, Kaur S, Soto-Pantoja DR, Basudhar D, Heinecke JL, Stewart CA, DeGraff W, Sowers AL, Thetford A, Kesarwala AH, Roberts DD, Young HA, Mitchell JB, Trinchieri G, Wiltrout RH, Wink DA: NOS Inhibition Modulates Immune Polarization and Improves Radiation-Induced Tumor Growth Delay. Cancer Res 2015;75:2788-2799.

13 Furugaki K, Fukumura J, Iwai T, Yorozu K, Kurasawa M, Yanagisawa M, Moriya Y, Yamamoto K, Suda K, Mizuuchi H, Mitsudomi T, Harada N: Impact of bevacizumab in combination with erlotinib on EGFRmutated non-small cell lung cancer xenograft models with T790M mutation or MET amplification. Int J Cancer 2016;138:1024-1032.

-14 Wang W, Xu X, Wang W, Shao W, Li L, Yin W, Xiu L, Mo M, Zhao J, He Q He J: The expression and clinical significance of CLIC1 and HSP27 in lung adenocarcinoma. Tumour Biol 2011;32:1199-1208.

$\checkmark 15$ Chang YH, Wu CC, Chang KP, Yu JS, Chang YC, Liao PC: Cell secretome analysis using hollow fiber culture system leads to the discovery of CLIC1 protein as a novel plasma marker for nasopharyngeal carcinoma. J Proteome Res 2009;8:5465-5474.

16 Wang L, He S, Tu Y, Ji P, Zong J, Zhang J, Feng F, Zhao J, Zhang Y, Gao G: Elevated expression of chloride intracellular channel 1 is correlated with poor prognosis in human gliomas. J Exp Clin Cancer Res 2012;31:44.

17 Kang MK, Kang SK: Pharmacologic blockade of chloride channel synergistically enhances apoptosis of chemotherapeutic drug-resistant cancer stem cells. Biochem Biophys Res Commun 2008;373:539-544.

18 Wei X, Li J, Xie H, Wang H, Wang J, Zhang X, Zhuang R, Lu D, Ling Q Zhou L, Xu X, Zheng S: Chloride intracellular channel 1 participates in migration and invasion of hepatocellular carcinoma by targeting maspin. J Gastroenterol Hepatol 2015;30:208-216.

19 Hung WY, Huang KH, Wu CW, Chi CW, Kao HL, Li AF, Yin PH, Lee HC: Mitochondrial dysfunction promotes cell migration via reactive oxygen species-enhanced beta5-integrin expression in human gastric cancer SCM1 cells. Biochim Biophys Acta 2012;1820:1102-1110.

-20 Fukuda K, Saikawa Y, Yagi H, Wada N, Takahashi T, Kitagawa Y: Role of integrin alpha1 subunits in gastric cancer patients with peritoneal dissemination. Mol Med Rep 2012;5:336-340.

-21 Gao W, Xua J, Wang F, Zhang L, Peng R, Zhu Y, Tang Q, Wu J: Mitochondrial Proteomics Approach Reveals Voltage-Dependent Anion Channel 1 (VDAC1) as a Potential Biomarker of Gastric Cancer. Cell Physiol Biochem 2015;37:2339-2354.

-22 Tanaka N, Fukuzawa M: MYCN downregulates integrin alpha1 to promote invasion of human neuroblastoma cells. Int J Oncol 2008;33:815-821.

23 Nakada M, Nambu E, Furuyama N, Yoshida Y, Takino T, Hayashi Y, Sato H, Sai Y, Tsuji T, Miyamoto KI, Hirao A, Hamada JI: Integrin alpha3 is overexpressed in glioma stem-like cells and promotes invasion. Br J Cancer 2013;108:2516-2524.

24 Xuan SH, Zhou YG, Pan JQ, Zhu W, Xu P: Overexpression of integrin alphav in the human nasopharyngeal carcinoma associated with metastasis and progression. Cancer Biomark 2013;13:323-328.

25 Ha SY, Shin J, Kim JH, Kang MS, Yoo HY, Kim HH, Um SH, Kim SH: Overexpression of integrin alphav correlates with poor prognosis in colorectal cancer. J Clin Pathol 2014;67:576-581.

-26 Yim DH, Zhang YW, Eom SY, Moon SI, Yun HY, Song YJ, Youn SJ, Hyun T, Park JS, Kim BS, Lee JY, Kim YD, Kim H: ITGA1 polymorphisms and haplotypes are associated with gastric cancer risk in a Korean population. World J Gastroenterol 2013;19:5870-5876. 


\section{Cellular Physiology Cell Physiol Biochem 2018;46:907-924 \begin{tabular}{l|l} 
and Biochemistry & $\begin{array}{l}\text { DOI: 10.1159/000488822 } \\
\text { Publised 2018 The Author(s). Published by S. Karger AG, Basel } \\
\text { www.karger.com/cpb }\end{array}$
\end{tabular}

Li et al.: CLIC1 Promotes the Progression of Gastric Cancer

27 Saito Y, Sekine W, Sano R, Komatsu S, Mizuno H, Katabami K, Shimada K, Oku T, Tsuji T: Potentiation of cell invasion and matrix metalloproteinase production by alpha3beta1 integrin-mediated adhesion of gastric carcinoma cells to laminin-5 C Clin Exp Metastasis 2010;27:197-205.

28 Zhuang Z, Zhou R, Xu X, Tian T, Liu Y, Liu Y, Lian P, Wang J, Xu K: Clinical significance of integrin alphavbeta6 expression effects on gastric carcinoma invasiveness and progression via cancer-associated fibroblasts. Med Oncol 2013;30:580.

-29 Rainero E, Norman JC: Late endosomal and lysosomal trafficking during integrin-mediated cell migration and invasion: cell matrix receptors are trafficked through the late endosomal pathway in a way that dictates how cells migrate. Bioessays 2013;35:523-532.

30 De Franceschi N, Hamidi H, Alanko J, Sahgal P, Ivaska J: Integrin traffic - the update. J Cell Sci 2015;128:839852.

-31 Ren J, Xu S, Guo D, Zhang J, Liu S: Increased expression of alpha5beta1-integrin is a prognostic marker for patients with gastric cancer. Clin Transl Oncol 2014;16:668-674.

32 Xu Y, Jin X, Huang Y, Dong J, Wang H, Wang X, Cao X: Inhibition of peritoneal metastasis of human gastric cancer cells by dextran sulphate through the reduction in HIF-1alpha and ITGbeta1 expression. Oncol Rep 2016;35:2624-2634.

33 Setti M, Savalli N, Osti D, Richichi C, Angelini M, Brescia P, Fornasari L, Carro MS, Mazzanti M, Pelicci G: Functional role of CLIC1 ion channel in glioblastoma-derived stem/progenitor cells. J Natl Cancer Inst 2013;105:1644-1655.

34 Gryko M, Pryczynicz A, Guzinska-Ustymowicz K, Kamocki Z, Zareba K, Kemona A, Kedra B: Immunohistochemical assessment of apoptosis-associated proteins: p53, Bcl-xL, Bax and Bak in gastric cancer cells in correlation with clinical and pathomorphological factors. Adv Med Sci 2012;57:77-83.

-35 Pasterkamp RJ, Peschon JJ, Spriggs MK, Kolodkin AL: Semaphorin 7A promotes axon outgrowth through integrins and MAPKs. Nature 2003;424:398.

36 Neal CL, McKeithen D, Odero-Marah VA: Snail negatively regulates cell adhesion to extracellular matrix and integrin expression via the MAPK pathway in prostate cancer cells. Cell Adh Migr 2011;5:249-257.

37 Saisongkorh V, Maiuthed A, Chanvorachote P: Nitric oxide increases the migratory activity of non-small cell lung cancer cells via AKT-mediated integrin alphav and beta1 upregulation. Cell Oncol (Dordr) 2016;39:449-462.

38 Jin F, Irshad S, Yu W, Belakavadi M, Chekmareva M, Ittmann MM, Abate-Shen C, Fondell JD: ERK and AKT signaling drive MED1 overexpression in prostate cancer in association with elevated proliferation and tumorigenicity. Mol Cancer Res 2013;11:736-747.

39 Zhao Y, Pang D, Wang C, Zhong S, Wang S: MicroRNA-134 modulates glioma cell U251 proliferation and invasion by targeting KRAS and suppressing the ERK pathway. Tumour Biol 2016;37:11485-11493.

40 Long QZ, Zhou M, Liu XG, Du YF, Fan JH, Li X, He DL: Interaction of CCN1 with alphavbeta3 integrin induces P-glycoprotein and confers vinblastine resistance in renal cell carcinoma cells. Anticancer Drugs 2013;24:810-817.

41 Robinson GL, Robinson JP, Lastwika KJ, Holmen SL, Vanbrocklin MW: Akt signaling accelerates tumor recurrence following ras inhibition in the context of ink4a/arf loss. Genes Cancer 2013;4:476-485.

-42 Yeh YC, Cheng HC, Yang HB, Chang WL, Sheu BS: H. pylori CagL-Y58/E59 prime higher integrin alpha5beta1 in adverse $\mathrm{pH}$ condition to enhance hypochlorhydria vicious cycle for gastric carcinogenesis. PLoS One 2013;8:e72735.

43 Kang HJ, Soh Y, Kim MS, Lee EJ, Surh YJ, Kim HR, Kim SH, Moon A: Roles of JNK-1 and p38 in selective induction of apoptosis by capsaicin in ras-transformed human breast epithelial cells. Int J Cancer 2003;103:475-482.

-44 HYE SEO JI, Kim KH, Kim H: Role of Proteinase-Activated Receptor-2 on Cyclooxygenase-2 Expression in H. pylori -Infected Gastric Epithelial Cells. Ann N Y Acad Sci 2007;1096:29-36.

45 Li W, Fan M, Chen Y, Zhao Q Song C, Yan Y, Jin Y, Huang Z, Lin C, Wu J: Melatonin Induces Cell Apoptosis in AGS Cells Through the Activation of JNK and P38 MAPK and the Suppression of Nuclear Factor-Kappa B: a Novel Therapeutic Implication for Gastric Cancer. Cell Physiol Biochem 2015;37:2323-2338. 